\title{
Heme oxygenase-1, oxidation, inflammation, and atherosclerosis
}

\author{
Jesus A. Araujo*, Min Zhang and Fen Yin \\ Division of Cardiology, Department of Medicine, David Geffen School of Medicine, University of California, Los Angeles, CA, USA
}

Edited by:

Mahin D. Maines, University of

Rochester School of Medicine, USA

Reviewed by:

Anderi Adrican Tica, University of

Medicine Craiova Romania, Romania

Jozsef Balla, University of Debrecen,

Hungary

Jawed Alam, Ochsner Clinic

Foundation, USA

*Correspondence:

Jesus A. Araujo, UCLA Division of Cardiology, Department of Medicine, David Geffen School of Medicine, 10833 Le Conte Avenue, CHS 43-264, Los Angeles, CA 90095, USA.

e-mail: jaraujo@mednet.ucla.edu
Atherosclerosis is an inflammatory process of the vascular wall characterized by the infiltration of lipids and inflammatory cells. Oxidative modifications of infiltrating low-density lipoproteins and induction of oxidative stress play a major role in lipid retention in the vascular wall, uptake by macrophages and generation of foam cells, a hallmark of this disorder. The vasculature has a plethora of protective resources against oxidation and inflammation, many of them regulated by the Nrf2 transcription factor. Heme oxygenase-1 (HO-1) is a Nrf2-regulated gene that plays a critical role in the prevention of vascular inflammation. It is the inducible isoform of $\mathrm{HO}$, responsible for the oxidative cleavage of heme groups leading to the generation of biliverdin, carbon monoxide, and release of ferrous iron. HO- 1 has important antioxidant, antiinflammatory, antiapoptotic, antiproliferative, and immunomodulatory effects in vascular cells, most of which play a significant role in the protection against atherogenesis. HO-1 may also be an important feature in macrophage differentiation and polarization to certain subtypes. The biological effects of HO-1 are largely attributable to its enzymatic activity, which can be conceived as a system with three arms of action, corresponding to its three enzymatic byproducts. HO-1 mediated vascular protection may be due to a combination of systemic and vascular local effects. It is usually expressed at low levels but can be highly upregulated in the presence of several proatherogenic stimuli. The HO-1 system is amenable for use in the development of new therapies, some of them currently under experimental and clinical trials. Interestingly, in contrast to the HO-1 antiatherogenic actions, the expression of its transcriptional regulator Nrf2 leads to proatherogenic effects instead. This suggests that a potential intervention on $\mathrm{HO}-1$ or its byproducts may need to take into account any potential alteration in the status of Nrf2 activation. This article reviews the available evidence that supports the antiatherogenic role of $\mathrm{HO}-1$ as well as the potential pathways and mechanisms mediating vascular protection.

\section{HEME OXYGENASE-1 AND VASCULAR INFLAMMATION: IMPORTANCE OF BASAL LEVELS}

Heme oxygenase $(\mathrm{HO})$ is a rate-limiting enzyme in the catabolism of heme. In association with cytochrome P450 reductase and in the presence of NADPH and three molecules of molecular oxygen $\left(\mathrm{O}_{2}\right)$ per heme molecule, it catalyzes the oxidative cleavage of heme (Fe-protoporphyrin-IX) to render equimolar amounts of biliverdin, ferrous iron $\left(\mathrm{Fe}^{2+}\right)$, and carbon monoxide (CO; Maines, 1997; Figure 1). Biliverdin can then be converted to bilirubin by the cytosolic enzyme biliverdin reductase (BVR). There are three $\mathrm{HO}$ isoforms (HO-1, HO-2, HO-3) that have been described (Siow et al., 1999), although HO-3 may be a pseudogene derived from HO-2 transcripts (Hayashi et al., 2004). While $\mathrm{HO}-2$ is constitutively expressed, $\mathrm{HO}-1$ is normally expressed at low levels in most tissues but it is highly inducible by a variety of stimuli. Indeed, HO-1 may be among the most critical cytoprotective mechanisms that are activated during times of cellular stress such as inflammation, ischemia, hypoxia, hyperoxia, hyperthermia, or radiation (Choi and Alam, 1996). It is thought to play a key role in maintaining antioxidant/oxidant homeostasis and in the prevention against vascular injury (Abraham and Kappas, 2008).

Cumulative evidence has shown that expression of HO-1 in the vasculature exerts protective effects against vascular inflammatory processes, thanks to its antioxidant, antiinflammatory, antiapoptotic, and possibly immunomodulatory properties. Thus, HO-1 antioxidant protection is particularly evident against the vascular inflammation occurring in models of antigen-independent ischemia reperfusion injury (IRI), where the reintroduction of oxygen after a period of ischemia and generation of reactive oxygen species (ROS) constitutes the central pathogenic event. Pharmacological competitive inhibitors of HO activity such as the heme analogs SnPPIX or ZnPPIX (Kato et al., 2001) or decreased HO-1 expression in genetically engineered $\mathrm{HO}-1^{+/-}$mice lead to significant worsening of IRI outcomes (Tsuchihashi et al., 2006). On the other hand, HO-1 overexpression by either pharmacological means or via genetic engineering has been reported to exert potent cytoprotective effects in hepatic IRI transplant models, with profoundly diminished proinflammatory and apoptotic responses (Amersi et al., 1999; Kato et al., 2001; Coito et al., 2002). 


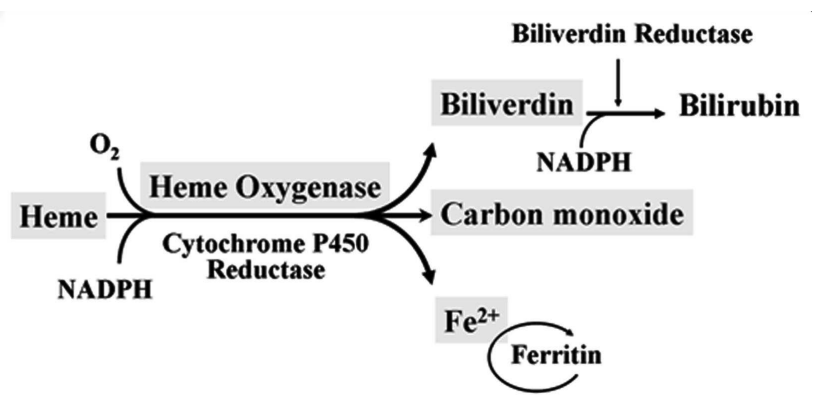

FIGURE 1 | Heme oxygenase enzymatic activity. HO enzymatic leads to the generation of biliverdin, release of carbon monoxide (CO) and $\mathrm{Fe}^{2+}$ Biliverdin is transformed into bilirubin by the biliverdin reductase (BVR) enzyme. $\mathrm{Fe}^{2+}$ can be bound by the iron storage protein ferritin.

Of importance, basal HO-1 levels, rather than the degree of HO-1 upregulation, appear to be crucial in the antioxidant cytoprotection as indicated by data obtained from $\mathrm{HO}-1^{+/-}$and $\mathrm{HO}-1^{+/+}$ mice subjected to partial liver warm ischemia for $90 \mathrm{~min}$ followed by $6 \mathrm{~h}$ of reperfusion (Tsuchihashi et al., 2006; Figure 2). Liver IRI injury is characterized by hepatocellular damage consisting in neutrophil infiltration, sinusoidal congestion, hepatocyte apoptosis/necrosis, and ballooning degeneration as well as impaired hepatocyte function that can be determined by elevation of serum transaminases such as the serum glutamic-oxaloacetic transaminase (sGOT) and the glutamic-pyruvic transaminase (sGPT). Treatment with CoPP (Cobalt Protoporhyrin), a synthetic analog of heme that induces HO-1 without competing for its catalytic site, led to upregulation in both basal (Figure 2A) and post-IRI HO-1 mRNA levels (Figure 2B) that led to decreased IRI overall, evidenced by decreased post-IRI serum transaminases. Interestingly, both basal (Figure 2C) and post-IRI HO-1 mRNA levels (Tsuchihashi et al., 2006) correlated negatively with sGPT levels but the degree of correlation was bigger with the basal $\left(R^{2}=0.87, p=0.0002\right)$ than with the post-IRI HO-1 levels $\left(R^{2}=0.55, p=0.0002\right)$. In addition, sGPT levels correlated positively with the degree of $\mathrm{HO}-1$ fold induction (Figure 2D), suggesting that the basal HO-1 levels (Figure 2A) may be more important than the degree of upregulation. However, this could also be due to the HO-1 behavior as a stress-responsive gene since it can be rapidly and highly upregulated by a large variety of acute stressors. Therefore, the degree of HO-1 fold induction might reflect the level of stress induced in the liver by the ischemia reperfusion rather than an ability to protect against the injury.

Heme oxygenase-1 antiinflammatory properties are clearly evident in models of organ transplantation, not only as a consequence of the protection against IRI but also by protecting against antigendependent immune responses. Thus, pharmacological inhibition (Hancock et al., 1998) or decreased HO-1 expression in mouse cardiac allografts lead to accelerated acute rejection, in parallel with similar results in mouse to rat xenografts (Soares et al., 1998). In addition, HO-1 overexpression in the cardiac allograft results in prolongation of the graft survival, which is much more dramatically improved when HO-1 is overexpressed in the recipient host rather than the donor organ (Araujo et al., 2003). It is possible then that HO-1 antiinflammatory properties involve specific immunomodulatory actions that could affect antigen presentation and/or shifting of the type of cellular immune response (Araujo et al., 2003; Chauveau et al., 2005). Interestingly, in a mouse model of heterotopic cardiac allograft transplantation, where $\mathrm{C} 57 \mathrm{BL} / 6 \mathrm{~J}$ hearts were transplanted into $\mathrm{BALB} / \mathrm{cByJ}$ recipients, hearts from $\mathrm{HO}-1^{ \pm}$mice, with HO-1 mRNA levels $\sim 60 \%$ of wild-type (WT) controls displayed shorter survival, despite a much larger degree of HO-1 upregulation after the transplant (unpublished), suggesting that basal HO-1 could be key in antiinflammatory protection. However, the different degree of $\mathrm{HO}-1$ fold induction in $\mathrm{HO}-1^{ \pm}$mice could also reflect here, as it does in the case of the IRI, a greater level of stress induced in the transplanted hearts by various inflammatory stressors rather than a different ability to protect against the rejection response.

This notion was further confirmed in human aortic endothelial cells (HAECs) from 149 individual donors treated with oxidized 1-palmitoyl-2-arachidonyl-sn-glycero-3phosphorylcholine (oxPAPC) as mentioned in more details below (Romanoski et al., 2011; Figure 3). In brief, baseline HO-1 mRNA levels, as judged by HAECs treated with media alone, exhibited a significant variation among different donors whereas treatment with oxPAPC resulted in significant upregulation of HO-1 levels that unlike baseline levels vary little in between donor cells (Figure 3B). oxPAPC treatment also led to the upregulation of several proinflammatory cytokines such as Interleukin (IL)-6. There was a negative correlation between basal HO-1 and levels of proinflammatory cytokines (Figure 3C). In addition, basal HO-1 levels were highly correlated with individual responsiveness to oxPAPC treatment at thresholds above 2-fold and 7.5-fold $(R=-0.57)$ when responsiveness was defined as the number of genes that were regulated above a given threshold per individual. This suggests that basal HO-1 levels are important in the protection against inflammation and in mitigating multiple cellular responses to oxPAPC (Romanoski et al., 2011).

The greater importance of basal HO-1 levels as compared to the level of upregulation has important implications, especially since these observations have been made in human primary cells that did not undergo any genetic manipulation. First, if basal HO- 1 expression is an important protective factor against vascular inflammation, why are the higher levels following induction unable to abrogate the inflammatory process? Second, how functional is the induced HO-1 protein? Third, what would be the ideal timing for potential therapeutic interventions and how should $\mathrm{HO}-1$ responses be assessed, by changes in the level of mRNA, protein, functional activity, or levels of its enzymatic byproducts? While it appears to be clear that HO-1 functional activity is important for its vascular protection as will be discussed in Section "HO System, Enzymatic Byproducts and Protection Against Atherosclerosis," there is a possibility that various stimuli or microenvironments could lead to changes in the specific enzymatic activity, which is the HO-1 enzymatic activity/HO-1 protein. Thus, Romanoski et al. (2011) showed that while oxPAPC treatment led to increased HO-1 mRNA, protein, and enzymatic activity in HAECs, the $\mathrm{HO}$ activity increased in a lesser degree than the HO-1 protein, suggesting a lower $\mathrm{HO}$ specific activity after treatment with oxPAPC as compared with basal levels. This is consistent with another study that showed a disparity between HO-1 protein and $\mathrm{HO}$ activity in a rat model of metabolic syndrome 

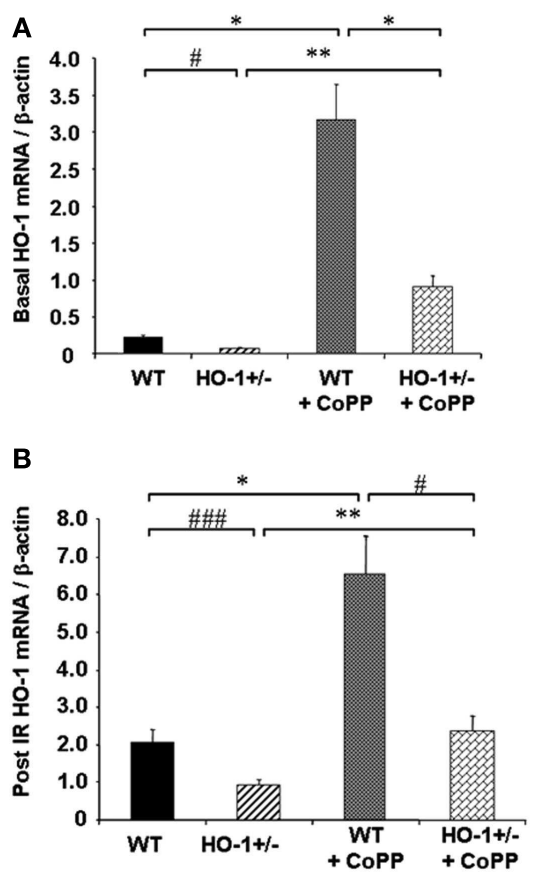

FIGURE 2 | Basal HO-1 protects against oxidation and inflammation. $\mathrm{HO}-1^{+/-}$and $\mathrm{HO}^{+/+}$(WT) mice were subjected to partial liver warm ischemia for $90 \mathrm{~min}$ followed by $6 \mathrm{~h}$ of reperfusion. Two groups of mice were treated with CoPP. (A) Basal HO-1 mRNA levels, (B) Post-ischemia reperfusion (IR) HO-1 mRNA levels, (C) Basal HO-1

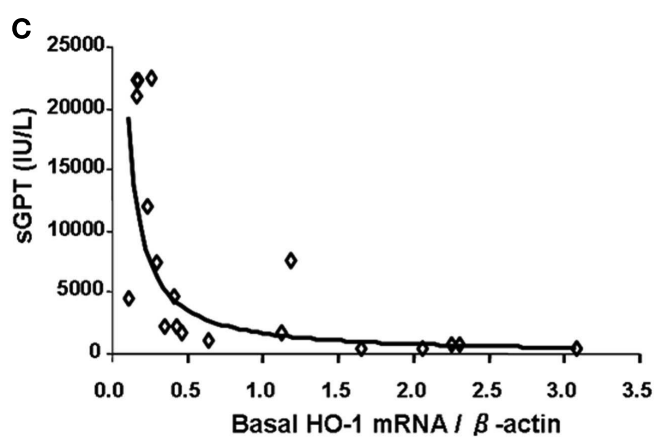

D

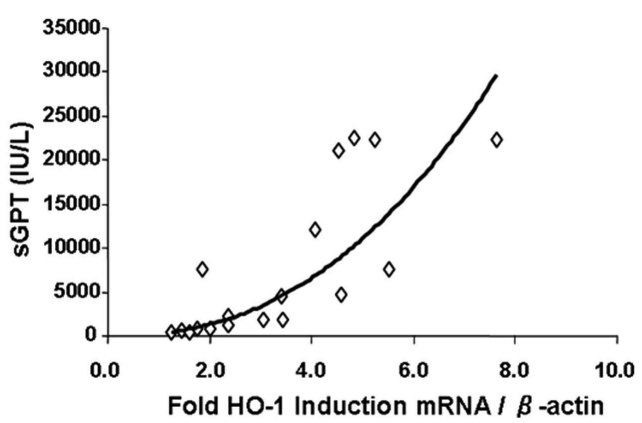

levels correlated negatively with post-IR serum GPT levels $\left(R^{2}=0.69\right.$, $p<0.0001$ ) (D) HO-1 fold induction had a positive correlation with sGPT levels instead $\left(R^{2}=0.75, p=0.0001\right)$. Taken from Tsuchihashi et al. (2006). Copyright 2006. The American Association of Immunologists, Inc.
A

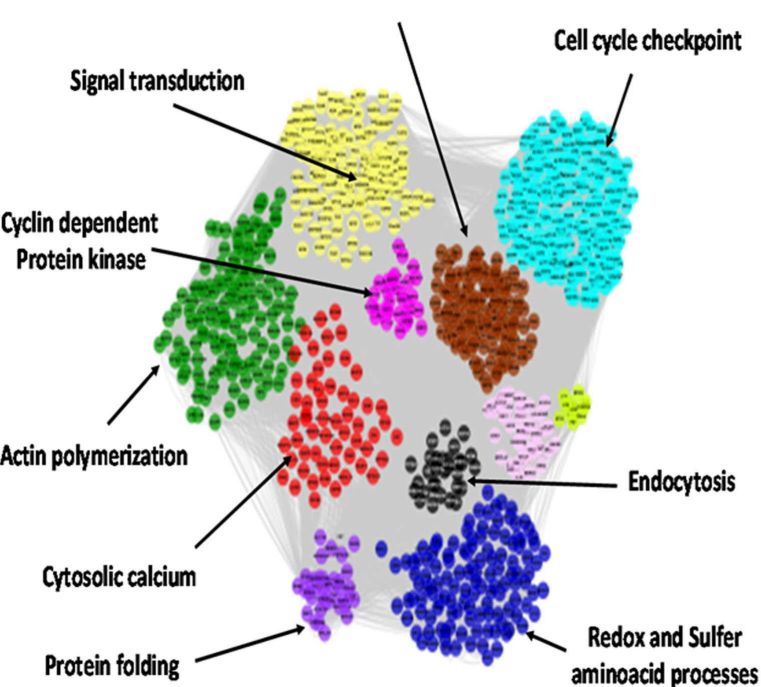

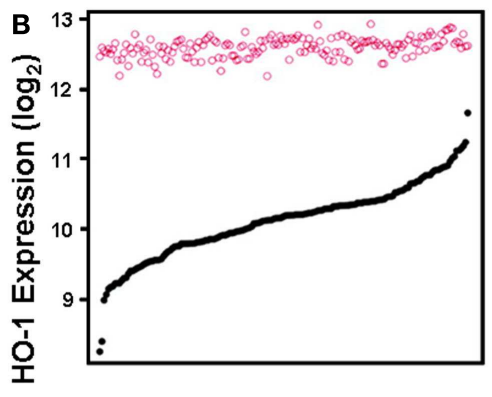

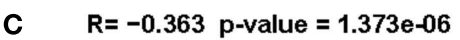

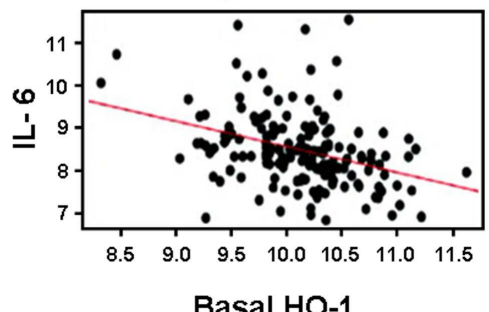

FIGURE 3 | Heme oxygenase-1 is a critical gene in the activation of endothelial cells by oxPAPC. (A) Visualization of the whole network consisting of 2000 transcripts, organized into 11 modules, shown by distinct colors. Network was constructed based on genomic expression data of HACEs from 149 donors, treated with oxPAPC. Examples of module enrichment in specific pathways are shown. HO-1 is a "hub" of gene-gene interactions in the blue module, enriched in redox and sulfur aminoacid processes. (B) HO-1 mRNA expression. Basal levels varied approximately ninefold at baseline (black curve) but only approximately twofold after treatment with oxPAPC (red circles). (C) Basal HO-1 mRNA levels correlated negatively with IL-6 mRNA expression. Taken from Romanoski et al. (2011). 
where HO-1 protein was likely modified by nitrosylation resulting in decreased functionality (Kruger et al., 2006). While our current understanding of the biology of HO-1 may not be sufficient to answer all these questions at the present time, the following sections attempt to provide information that we hope will help to address them.

\section{ROLE OF HO-1 AND OTHER ANTIOXIDANT GENES IN ATHEROSCLEROSIS}

Atherosclerosis is an inflammatory process of the vascular wall characterized by the accumulation of lipids and fibrous elements in large and medium-sized elastic and muscular arteries (Lusis, 2000). Infiltrating lipids come from circulating low-density lipoprotein (LDL) particles that are retained in the vascular wall. The retention of LDL is favored by its oxidative modification which leads to activation of endothelial cells, monocyte recruitment with internalization into the vasculature, differentiation into macrophages and generation of foam cells by increased lipid uptake. Vascular infiltration of lipids and inflammatory cells further enhances oxidative stress and a vicious cycle of inflammation (Araujo et al., 2002). While the pathogenic role of vascular oxidative stress has been challenged by the argument that oxidative modifications present in the plaques could be consequential rather than causal to lesion formation (Stocker and Keaney, 2004), it does appear that the interplay between prooxidant and antioxidant factors in the vasculature may determine the degree of ROS generation in a way that can affect lesion formation. Thus, established risk factors such as diabetes and cigarette smoking or novel risk factors such as exposure to air pollution enhance ROS generation in the vasculature and promote atherogenesis (Araujo, 2011). Part of these actions may be mediated by activation of NADPH oxidase, which has been shown to be an important source of vascular ROS and deficiency of its p47phox subunit results in decreased atherosclerotic lesion formation in ApoE null mice (Barry-Lane et al., 2001). On the other hand, organisms have numerous antioxidant resources that may protect against increased ROS formation in the vasculature. Some of them are in the circulating blood such as albumin, bilirubin, or plasma high-density lipoproteins (HDL) that can exert antioxidant protection. Others are within vascular cells and include a large number of antioxidant genes and phase2 detoxifying enzymes regulated by the transcription factor $\mathrm{Nrf} 2$ (NFE2 related factor 2). HO-1 is among those Nrf2-target genes, which is significantly expressed in all main cell types present in mouse and human atherosclerotic lesions, such as endothelial cells (EC), macrophages, and smooth muscle cells (SMCs; Wang et al., 1998; Ishikawa et al., 2001b).

\section{HEME OXYGENASE-1 AND OTHER ANTIOXIDANT GENES PROTECT AGAINST ATHEROSCLEROSIS}

The importance of HO-1 expression in the protection against human atherosclerotic lesions has been emphasized by various genetic population studies, which have shown that a GT length polymorphism in the promoter region of the human $\mathrm{HO}-1$ gene is related to susceptibility for atherosclerosis. Thus, a shorter number of repeats has been associated with decreased susceptibility to coronary artery disease (CAD) in diabetic Japanese (Kaneda et al., 2002) and Chinese (Chen et al., 2002) populations, abdominal aortic aneurysms (Schillinger et al., 2002) and post-angioplasty restenosis, in both coronary (Chen et al., 2004) and peripheral arteries (Exner et al., 2001) in comparison with a longer number of repeats. Short GT variants (S) are likely to result in increased HO-1 expression in comparison with long variants (L) as judged by reporter transfection assays (Yamada et al., 2000), even though the cutoff to differentiate between $S$ and $L$ variants have been different among various studies. This was confirmed in human umbilical vein endothelial cells (HUVECs). Cells carrying the $S$ allele exhibited higher levels of HO-1 mRNA, protein, and HO activity than cells carrying the $\mathrm{L}$ allele (Taha et al., 2010). While HO-1 deficiency is very rare in humans, additional confirmation of the importance of HO-1 against vascular inflammation derives from the first autopsy report of a HO-1 deficient 6-year-old boy who exhibited hyperlipidemia (Yachie et al., 1999), foamy macrophages in the liver as well as fatty streaks and fibrous plaques in the aorta (Kawashima et al., 2002). In addition, HO-1 deficiency led to very high concentrations of circulating heme and damage to vascular endothelium that was probably mediated through the generation of oxidized forms of LDL (Jeney et al., 2002) which could have contributed to atherosclerotic lesion formation. It is unclear however whether these changes can be solely attributed to HO-1 deficiency since this boy had undergone a long-term steroid treatment for a presumptive diagnosis of juvenile rheumatoid arthritis that was not confirmed upon pathological examination (Kawashima et al., 2002).

We and others have shown that HO-1 is an antiatherogenic gene in animal models (Ishikawa et al., 2001a,b; Juan et al., 2001; Yet et al., 2003; Orozco et al., 2007) as summarized in Table 1. Systemic lack of HO- 1 has been reported to promote atherosclerosis in ApoE null mice (Yet et al., 2003) as well as aortitis in chow-fed old C57BL/6 mice (Ishikawa et al., 2012), while its overexpression by adenoviral means results in decreased atherosclerotic lesions (Juan et al., 2001). Likewise, pharmacological manipulation of the gene results in similar effects. Thus, administration of hemin results in significant HO-1 upregulation and decreased atherogenesis in LDLR $^{-1-}$ mice (Ishikawa et al., 2001b), ApoE ${ }^{-1-}$ mice (Cheng et al., 2009), and rabbits fed a high fat diet (Li et al., 2011; Liu et al., 2012). Since increased expression of HO-1 carries the danger of increased release of ferrous iron $\left(\mathrm{Fe}^{2+}\right)$ and exacerbation of ironmediated ROS formation, Ishikawa et al. (2001b) administered iron-chelating deferoxamine to $\mathrm{LDLR}^{-1-}$ mice that were treated with hemin to avoid this potential problem. However, subsequent studies in $\mathrm{ApoE}^{-1-}$ mice and rabbits showed that this was not necessary (Cheng et al., 2009; Li et al., 2011; Liu et al., 2012). This is likely due to the fact that HO-1 upregulation colocalizes with increased expression of ferritin in atherosclerotic lesions, which may ensure safe disposal of the released $\mathrm{Fe}^{2+}$.

On the other hand, inhibition of HO enzymatic activity by SnPPIX leads to enhanced atherosclerotic lesions in LDL- $\mathrm{R}^{-1-}$ mice (Ishikawa et al., 2001b), Watanabe hyperlipidemic rabbits (Ishikawa et al., 2001a) and rabbits fed a high fat diet (Li et al., 2011; Liu et al., 2012; Table 1). In addition, inhibition of HO enzymatic activity by ZnPPIX augmented plaque vulnerability in ApoE null mice by decreasing the relative cap thickness and intimal surface area of SMC, at the same time of increasing the lipid content and the degree of core necrosis (Cheng et al., 2009). It is clear then that modulation of HO-1 expression significantly alters atherogenesis in various animal models. The different degrees how atherogenesis 


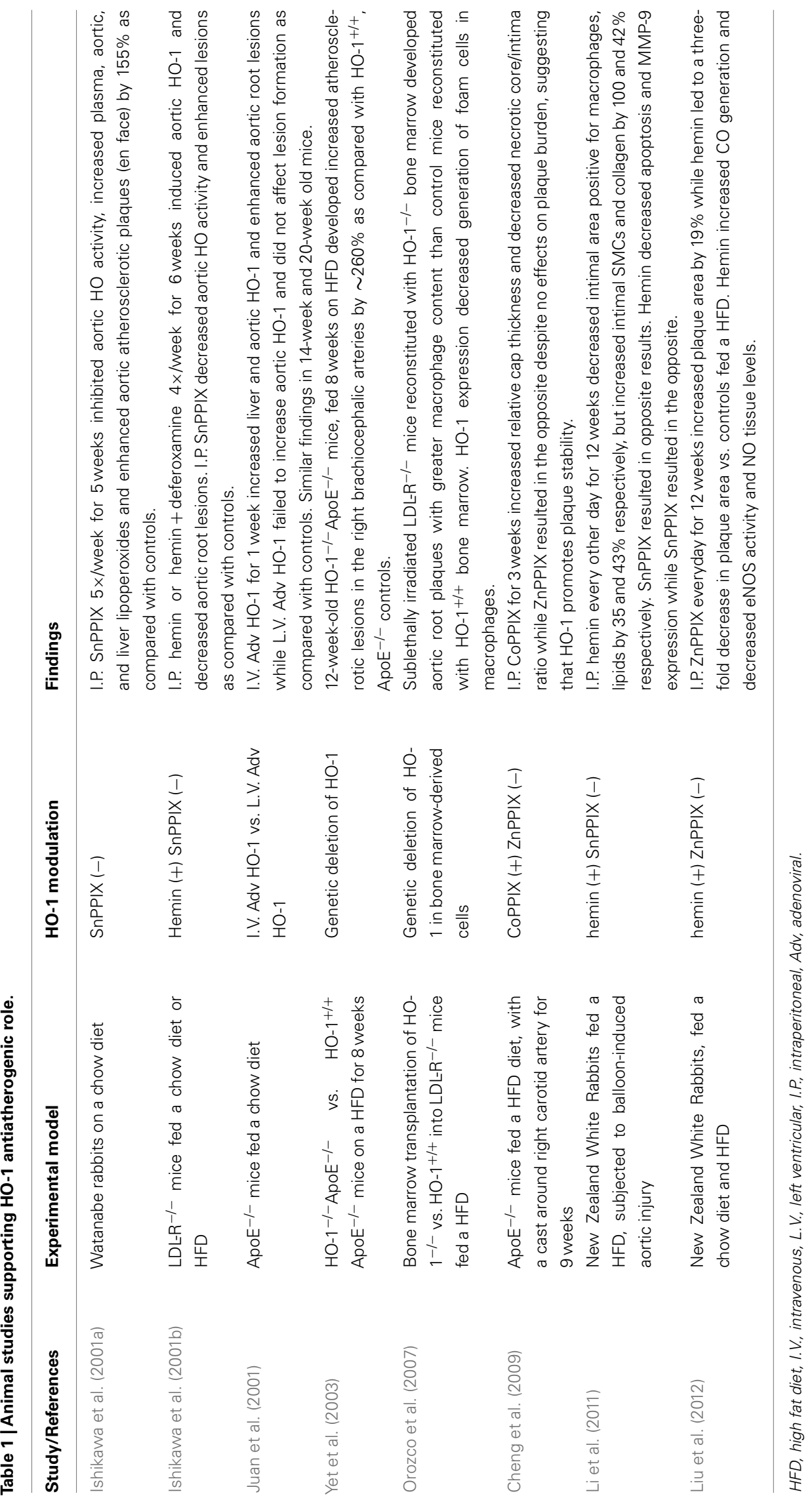


was affected in all these studies may have to do with differences in the experimental designs and the inherent characteristics of the animal models employed (Table $\mathbf{1}$ ).

As ROS generation and tissue oxidative stress have been implicated in all stages of atherosclerosis, it appears that HO-1 expression is protective against the development of both early and advanced atherosclerotic plaques. HO-1 antioxidant and antiinflammatory properties may be crucial against the development of early plaques (Ishikawa et al., 2001b, 2012; Orozco et al., 2007), while its antiapoptotic activities can be important in lesion progression and/or plaque vulnerability for rupture (Cheng et al., 2009; Li et al., 2011). Interestingly, HO-1 expression could inhibit maturation of dendritic cells (Chauveau et al., 2005) and may modulate antigen presentation and participate in macrophage differentiation/polarization, phenomena that could be particularly important in the development of early stage lesions. On the other hand, as intraplaque hemorrhage and accumulation of heme/iron are an important component in lesion progression, HO-1 expression could be important to ensure catabolism of the heme groups and recycling of iron, which could affect the development of advanced plaques as well.

Heme oxygenase-1 antiatherogenic properties parallel its vascular protective effects in other models of vascular inflammation such as post-angioplasty restenosis (Duckers et al., 2001; Tulis et al., 2001), allograft rejection (Araujo et al., 2003), and ischemia reperfusion (Tsuchihashi et al., 2006). Like HO-1, other Nrf2-regulated antioxidant genes such as glutamate-cysteine ligase, modifier subunit $(\mathrm{Gclm})$, glutamate-cysteine ligase, catalytic subunit (Gclc), peroxiredoxin 2, glutathione peroxidase, have been shown to protect against atherosclerosis. Thus, while deficiency of Gclm accelerates advanced atherosclerosis in ApoE null mice, overexpression of Gclc results in the opposite (Callegari et al., 2011). Systemic deficiency of peroxiredoxin or in bone marrow-derived cells enhances atherosclerotic lesions in ApoE null mice (Park et al., 2011). Similarly, deficiency of glutathione peroxidase exacerbates diabetes mellitus-associated atherogenesis in ApoE null mice (Lewis et al., 2007). On the other hand, adenoviral administration of endothelial cell Superoxide dismutase (EC-SOD; Laukkanen et al., 2002; Brasen et al., 2007), CuZnSOD (Durand et al., 2005), and catalase (Durand et al., 2005) inhibit post-angioplasty restenosis instead. Overall, HO- 1 and several antioxidant genes, all regulated by Nrf2, exert protection against atherosclerosis.

\section{Nrf2 TRANSCRIPTION FACTOR PARADOXICALLY PROMOTE ATHEROSCLEROSIS}

The substantial evidence in support of the antiatherogenic role of several Nrf2-regulated antioxidant genes led to the hypothesis that this transcription factor should play an inhibitory role of atherogenesis as well. Surprisingly, we and others have reported three separate studies showing that Nrf2 deficiency in gene-targeted mice leads to decreased atherosclerotic lesions in ApoE null mice (Sussan et al., 2008; Barajas et al., 2011; Freigang et al., 2011), suggesting that its expression may play a proatherogenic role despite its antioxidant actions. $\mathrm{Nrf} 2^{-I-} \mathrm{ApoE}^{-I-}$ mice developed reduced aortic atherosclerosis as compared to $\mathrm{Nrf}^{+/-} \mathrm{ApoE}^{-1-}$ (Barajas et al., 2011; Freigang et al., 2011) or Nrf2 ${ }^{+/+} \mathrm{ApoE}^{-/-}$controls (Sussan et al., 2008; Barajas et al., 2011). The type of diet appears to be an important modulating factor as these effects were only seen in males when mice were fed a chow diet (Barajas et al., 2011).

Various putative mechanisms, as shown in Figure 4, could mediate Nrf2 proatherogenic effects as recently discussed in an editorial article (Araujo, 2012): (1) Nrf2 expression leads to increased levels of plasma non-HDL cholesterol in Chow-fed ApoE null mice, likely via enhancing liver lipogenesis (Huang et al., 2010; Barajas et al., 2011), (2) Nrf2 promotes foam cell formation, partially due to upregulation of the CD36 scavenger receptor (Ishii et al., 2004; Barajas et al., 2011), (3) Nrf2 enhances increased expression of IL- $1 \alpha$ in macrophages which may promote greater monocyte migration to the lesions (Burns and Furie, 1998; Freigang et al., 2011), and (4) Nrf2 may regulate the differentiation of macrophages to subtypes different to the classical M1 and M2, named Mox (Kadl et al., 2010) and possibly Mhem (Boyle et al., 2011, 2012), with functions in atherosclerotic lesion formation still to be determined.

The opposite effects of HO-1 and Nrf2 in atherogenesis shown in Figure 4, underline the high degree of complexity of pathways involved in the response to prooxidative and proatherogenic stimuli. In addition, it appears that the level of regulation or intervention upon these responses is quite important as downstream interventions such as deletion of antioxidant genes like $\mathrm{HO}-1$ result in exacerbation of atherosclerosis but a more upstream level of intervention, such as deletion of Nrf2 transcription factor, results in the opposite. It is therefore quite important to understand how HO-1, as well as other antioxidant genes, exert their antiatherogenic effects.

\section{HEME OXYGENASE-1 ANTIATHEROGENIC EFFECTS: SYSTEMIC VS. VASCULAR MECHANISMS}

Heme oxygenase- 1 is ubiquitously expressed and highly upregulated in all the main cell types present in human (Wang et al., 1998) and murine atherosclerotic lesions (Ishikawa et al., 2001b), including endothelial cells, macrophages, and SMCs, but it is very low in neighboring unaffected vascular tissue. Such upregulation is particularly noticeable in macrophages, foam cells, and endothelial cells (Ishikawa et al., 2001b). The overall protective effects of HO-1 have been well documented and the subject of recent reviews (Morita, 2005; Abraham and Kappas, 2008; Soares and Bach, 2009; Durante, 2011) but the importance of the tissue and cellular localization as well as precise mechanisms responsible for these effects remain unclear. Several studies have addressed the role of HO-1 in atherogenesis as mentioned in the previous section (Table 1). For the most part, these studies have used systemic modulation of either HO-1 expression and/or HO activity, which occurs in both vascular and non-vascular cells, with subsequent alteration of oxidant and inflammatory parameters in the circulating blood. It is possible that $\mathrm{HO}-1$ antiatherogenic actions are due to a combination of systemic and local vascular mechanisms.

\section{SYSTEMIC EFFECTS}

Systemic modulation of HO-1 expression levels or activity can lead to changes in the systemic levels of its enzymatic byproducts that could mediate some of the effects in the vasculature. Thus, systemic transgenic mice that overexpressed HO- 1 by only $\sim 30-50 \%$ 


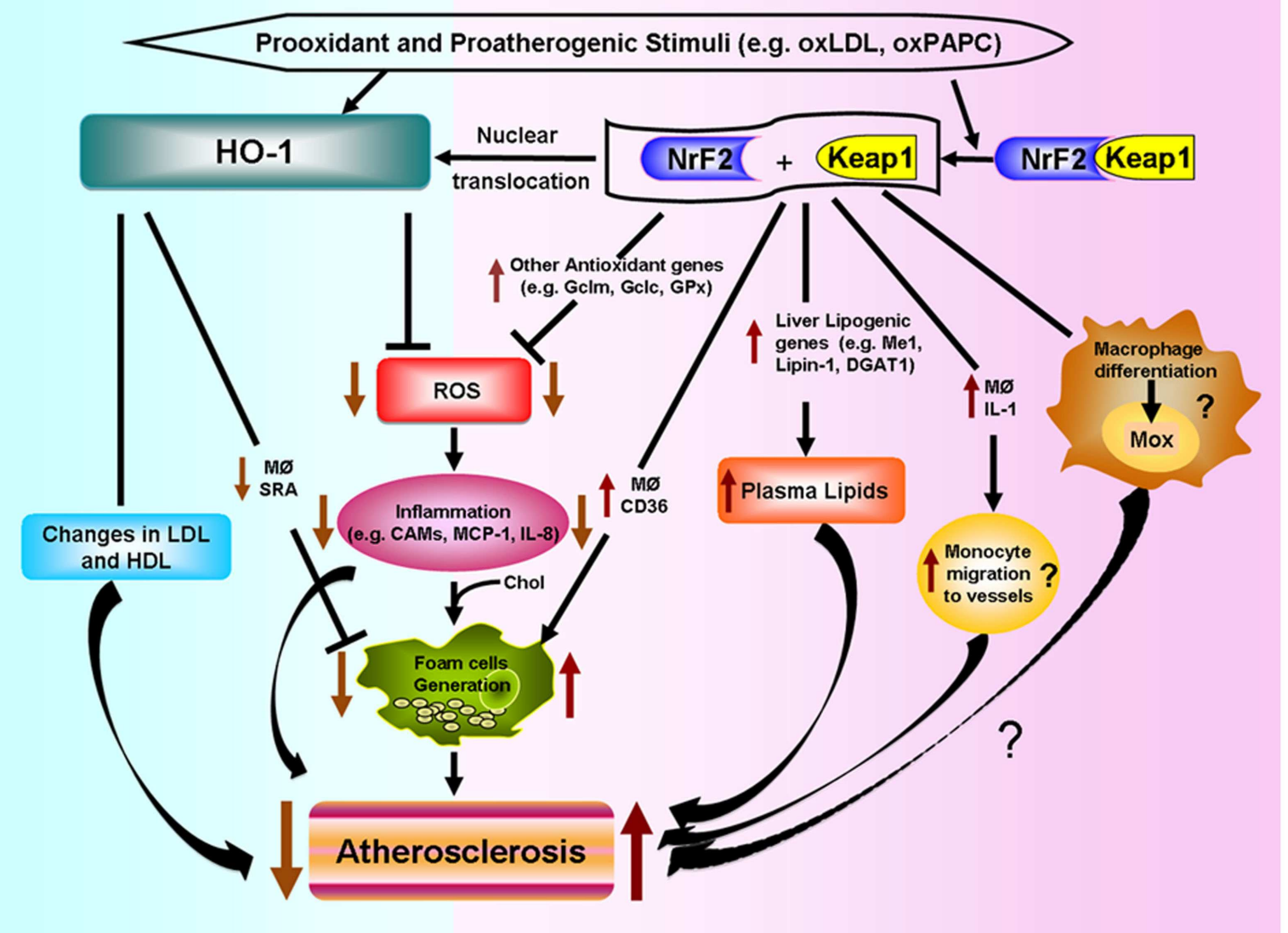

FIGURE 4 | Differential effects of HO-1 and NRF2 in atherosclerosis. Prooxidant and proatherogenic stimuli such as OxLDL and oxPAPC can induce HO-1 expression in vascular cells via Nrf2 activation or other pathways. HO-1 expression leads to decreased ROS generation, decreased inflammatory events such as lower expression of cell adhesion molecules (CAMs) and decreased secretion of inflammatory factors such as monocyte chemotactic protein (MCP)-1 and IL-8. HO-1 also leads to decreased foam cell formation and changes in LDL and HDL lipoproteins, all of which lead to decreased atherogenesis. Nrf2 is bound by chaperone Keap1 in the cytosol. Electrophilic agents lead to dissociation of the Nrf2-Keap1 complex, with release of Nrf2 and nuclear translocation that leads to the induction of $\mathrm{HO}-1$ and several other antioxidant genes that result in decreased ROS formation. However, Nrf2 expression promotes atherosclerotic lesion development. Possible mechanisms include: (1) increased macrophage lipid uptake and foam cell formation, (2) increased lipogenesis and greater levels of non-HDL plasma cholesterol, (3) greater macrophage secretion of IL-1 and monocyte migration to the vessels, and (4) possible macrophage differentiation into a proatherosclerotic phenotype. in the liver over WT controls, exhibited a modest increase in blood unconjugated bilirubin (Araujo et al., 2003). Likewise, I.P. treatment of rabbits with hemin for 12 weeks led to increased HbCo levels while I.P. treatment with inhibitor SnPPIX for similar time led to the opposite (Li et al., 2011). In humans, small variations in bilirubin levels translate into clinical effects.

Changes in blood or vascular concentrations of $\mathrm{HO}$ byproducts could lead to alterations in plasma lipoproteins that may affect susceptibility to atherogenesis. Indeed, HO-1 null mice exhibit increased levels of plasma lipid peroxides (Ishikawa et al., 2012) that are parallel to their increased levels of lipid peroxides and protein carbonyls in the liver and kidneys (Poss and Tonegawa, 1997). Likewise, inhibition of $\mathrm{HO}$ activity by ZnPPIX leads to increased serum levels of oxLDL (Liu et al., 2012). It is possible that HO-1 deficiency or inhibition of $\mathrm{HO}$ enzymatic activity could lead to increased levels of circulating heme which may mediate lipid peroxidation in plasma lipoproteins, resulting in oxidized LDL (Balla et al., 1991) and lipid oxidation in atherosclerotic plaques (Nagy et al., 2010). Indeed, the 6-year-old boy, deficient in HO-1, was reported to have chronic intravascular hemolysis (Yachie et al., 1999) resulting in very high concentrations of circulating heme and a high proportion of methemoglobin (Jeney et al., 2002). The latter is a form of the oxygen-carrying hemoglobin that can not bind oxygen and releases iron in a greater degree than the normal oxy-hemoglobin with the subsequent potential of promoting oxidative injury and endothelial cell toxicity (Jeney et al., 2002). Therefore, HO-1 mediated disposal of heme groups may help to decrease systemic lipid peroxidation, generation of oxidized LDL and cellular injury (Figure 4).

Heme oxygenase-1 systemic effects also appear to involve HDL lipoproteins as HO-1 null mice exhibit decreased levels of paraoxonase activity and altered ratio of apoAI to apoAII proteins, which are likely to alter HDL function (Ishikawa et al., 2012). Therefore, HO-1 expression may protect against LDL oxidation or decrease 
its susceptibility to oxidation as it alters HDL protective qualities (Figure 4). In addition, HO-1 expression may also affect inflammatory mediators at a systemic level, as $\mathrm{HO}-1$ null mice have been reported to exhibit greater plasma levels of monocyte chemotactic protein (MCP)-1 protein and increased levels of MCP-1 mRNA in circulating leukocytes as compared with wild-type mice (Pittock et al., 2005).

Heme oxygenase- 1 and BVR, the latter responsible for the conversion of biliverdin into bilirubin, have been reported to exert beneficial effects in metabolic pathways. For instance, BVR has been shown to be a member of the insulin receptor substrate family (Lerner-Marmarosh et al., 2005) with pleiotropic functions that include effects on metabolism and cytoprotection (Kapitulnik and Maines, 2009). In addition, HO-1 has been shown to be induced by apoAI mimetic peptides and mediate some of their beneficial effects on decreasing endothelial cell sloughing and improving vascular reactivity in a rat model of diabetes (Kruger et al., 2005). Whether these effects are due to a systemic or a vascular level of action is not clear. HO-1 null mice do not exhibit alteration of plasma glucose and/or lipid levels indicative of overt diabetes, glucose intolerance, or other frank metabolic disorders. It might be possible that HO-1 deficient mice may experience upregulation of other compensatory mechanisms that could inhibit the development of obvious metabolic abnormalities.

In addition to these systemic effects, it also appears that vascular local expression is important. Indeed, adenoviral HO-1 overexpression via intracardiac administration, resulting in both aortic and liver overexpression, confers protection against atherosclerosis whereas tail vein administration, only resulting in hepatic but not aortic overexpression, does not (Juan et al., 2001). Although the contribution of systemic effects can not be ruled out by this approach since adenoviral administration via tail vein may have elicited a degree of systemic inflammation that could have masked the effects of sole hepatic HO-1 overexpression, the study does underline the importance of $\mathrm{HO}-1$ expression in the vasculature.

\section{ENDOTHELIAL CELLS}

The vessels contain a monolayer of endothelial cells which represent the first cellular component that any infiltrating lipid or inflammatory cell encounter as they enter the vascular wall. The activation of endothelial cells leading to the expression of cell adhesion molecules (CAMs) and proinflammatory factors may be key in atherogenesis. Therefore, HO-1 expression in endothelial cells can be an important factor in the prevention against atherosclerosis. Indeed, Romanoski et al. (2011) recently reported that HO-1 expression in endothelial cells constitutes a critical gene in the global response of endothelial cells against oxidized phospholipids. In this study, a "systems-level" approach was used to understand the multiplicity of pathways that are elicited in HAECs, from 149 donors, in response to a treatment with oxPAPC, products of the oxidation of phospholipid PAPC (1-palmitoyl-2-arachidonylsn-glycero-3-phosphorylcholine), which are generated during the oxidation of LDL particles and known to induce HO-1. The approach took advantage of naturally occurring genetic variations in the human population that perturbed individual gene expression patterns with and without oxPAPC treatment, which enabled the construction of a gene co-expression network, consisting of
11 modules (groups) of tightly connected genes. Some genes exhibited many more connections than others ("hubs"), which in general, appear to be much more important in the functioning of the cell/organism as a whole. Notably, HO-1 emerged as a "hub" in one of the most interesting modules (blue module, Figure 3A), with various degrees of connection with other antioxidant genes (e.g. NQO1, Gclm), unfolded protein response (UPR) as well as transcription factors (e.g. Nrf2, MAFF).

This approach not only helped to identify novel factors that could be involved in the regulation of human HO-1 such as G-protein coupled receptor (GPR)-39 but also unraveled clues about the dynamics of the HO-1 response to oxPAPC in human subjects. While HAECs from the 149 donors exhibited a ninefold difference between extremes of HO-1 expression, they only exhibited a twofold difference after treatment with oxPAPC, suggesting that there was a ceiling to oxPAPC-induced $\mathrm{HO}$ 1 expression in this system. Importantly, basal HO- 1 expression levels, rather than HO-1 levels after oxPAPC treatment, strongly correlated negatively with the expression of proinflammatory cytokines such as IL-6 $(r=-0.36, p=1.37 e-06)$, IL-8 $(r=-0.28, p=2.41 e-04)$, CAMs such as VCAM1 $(r=-0.22$, $p=3.31 e-03)$, UPR such as Activating factor (ATF) $3(r=-0.40$, $p=5.01 e-08)$. Silencing of HO-1 by siRNA resulted in upregulation of many of the same genes (Romanoski et al., 2011). Altogether, this suggests that basal HO-1 levels are major determinants in the protection against inflammation and possibly atherogenesis, in parallel with our similar findings in the models of liver ischemia reperfusion (Tsuchihashi et al., 2006) and cardiac allograft rejection (see Heme Oxygenase-1 and Vascular Inflammation: Importance of Basal Levels). In addition, it will be important to determine whether GPR39 or other genetic factors could help explain the ninefold difference observed in basal HO-1 in HAECs, especially since the (GT)n polymorphisms data could not explain that variation (Romanoski et al., 2011).

Heme oxygenase-1 expression in endothelial cells leads to decreased expression of vascular cell adhesion molecule-1 (VCAM-1) as well as the expression and release of chemokines and proinflammatory cytokines such as CC-chemokine ligand (CCL)2, also known as MCP-1 (Sacerdoti et al., 2005). Taha et al. also reported that HUVECs collected from individuals exhibited differences in their basal (unstimulated) HO-1 levels that were dependent on their genotype for the (GT)n microsatellite DNA. In this study, alleles were classified as Short (S), Medium (M), and Long (L) based on the number of GT repeats, $\leq 23,24-28$, and $\geq 29$ repeats, respectively. Cells carrying the $S$ allele exhibited higher HO-1 basal levels than those carrying the $\mathrm{M}$ and/or L alleles. Likewise, similar differences in expression levels ensued after treatment with $\mathrm{H}_{2} \mathrm{O}_{2}$, CoPP, LPS, 15d-PGJ 2 b but not after treatment with hemin or in the presence of hypoxia where there were no differences. Here also, cells with the $\mathrm{S}$ allele, with higher basal HO-1 levels exhibited lower basal levels of IL1 $\beta$, IL-6, and ICAM1 (Taha et al., 2010). Despite the potential differences in behavior between endothelial cells in culture and those in the vascular wall in vivo, these studies support a protective role for $\mathrm{HO}-1$ expression in endothelial cells that could represent a significant portion of its protection against atherogenesis. 
Heme oxygenase-1 expression in endothelial cells could also play a role in the protection against atherosclerosis induced by environmental factors such as smoking and exposure to air pollution, which has been shown to lead to increased atherosclerosis in several animal models (Araujo, 2011). Indeed, it is upregulated in systemic tissues in response to the exposure to ambient ultrafine particles and its upregulation in a cell line of human microvascular endothelial cells, in response to oxPAPC and diesel exhaust particle (DEP) chemicals, occurs in a synergistic manner (Gong et al., 2007). It remains to be determined whether HO-1 plays indeed a protective role in this context.

\section{MACROPHAGES, DENDRITIC CELLS, AND LYMPHOCYTES}

Macrophages are the main inflammatory cells that infiltrate the vascular wall in atherogenesis, involved in the initiation as well as progression of atherosclerotic lesions. Upon activation of endothelial cells, blood monocytes are recruited to the site of injury and/or EC activation where cytokines and/or chemokines are released, adhere to the endothelium and transmigrate to the subendothelial space where they further differentiate into macrophages. HO-1 is highly upregulated in macrophages in atherosclerotic lesions and several lines of evidence support its protective antiatherogenic role in these cells. First, HO-1 has been shown to exert antioxidant and antiinflammatory effects in macrophages (Lee et al., 2003; Philippidis et al., 2004; Levonen et al., 2007; Orozco et al., 2007). Indeed, we have reported that decreased or absent HO-1 expression in peritoneal macrophages results in enhanced ROS formation and increased inflammatory cytokines such as MCP-1, interleukin 6 (IL-6), and the murine interleukin 8 homolog (KC; Orozco et al., 2007; Figure 5A). Second, HO-1 expression influences lipid loading and foam cell formation as both partial and total HO-1 deficiency results in enhanced lipid loading and foam cell formation in peritoneal macrophages treated with oxLDL, at least partially mediated by increased expression of the scavenger receptor A (SR-A; Orozco et al., 2007). Third, lack of HO-1 expression in bone marrow-derived cells resulted in atherosclerotic plaques with a larger inflammatory component, suggestive of greater vulnerability for rupture (Orozco et al., 2007). Irradiated LDL- $\mathrm{R}^{-/-}$mice with their bone marrow reconstituted with $\mathrm{HO}-1^{-1-}$ donor cells resulted in plaques with increased macrophage area as compared with control mice reconstituted with WT bone marrow (Orozco et al., 2007). Fourth, HO-1 expression may play a role in macrophage differentiation and polarization (Figure 5B).

Heme oxygenase- 1 antiatherogenic actions may also be due to its expression in other myelocytic or lymphocytic cells. Thus, it has been shown that HO-1 is expressed in immature dendritic cells and its overexpression inhibits dentritic cell maturation (Chauveau et al., 2005) which may play a role in atherogenesis. Several studies have highlighted a prominent role of dendritic cells in atherosclerotic lesions (Llodra et al., 2004; Yilmaz et al., 2004; Bobryshev, 2005) as they are present especially in regions of atherosclerotic plaques that are prone to rupture (Yilmaz et al., 2004) and its emigration from the lesions to lymph nodes associate with reduction in the size of atherosclerotic plaques (Llodra et al., 2004). Antigen presentation by dendritic cells as well as lymphocyte infiltration and the triggering of Th1 immune responses appear to play a role in atherosclerosis (Bobryshev, 2010; Manthey and Zernecke, 2011). Atherosclerotic lesion development is favored by Th1 responses while it is inhibited by conditions that promote a Th2 response (Minamino et al., 2001). HO-1 overexpression may lead to a switch from a Th1 to a Th2 response (Ke et al., 2000, 2001). These immunomodulatory actions parallel the effects of HO-1 expression against acute rejection response in models of allograft transplantation (Araujo et al., 2003). As macrophages can also function as antigen-presenting cells, they can play a role in the modulation of Th immune responses. Therefore, macrophage HO-1 expression could not only affect their function as effectors but also as presenting cells.

Macrophage differentiation, polarization, and function could indeed be affected by HO-1 expression. Upon differentiation, macrophages may polarize into distinct subsets with characteristic phenotypes and likely to exhibit different behaviors in atherosclerotic lesion formation, as schematized in Figure 5B. The first subtypes of polarized macrophages that were described were named as M1 and M2. Macrophages stimulated by lipopolysaccharide (LPS) or interferon gamma (IFN- $\gamma$ ) polarize into M1 macrophages, characterized by increased expression of proinflammatory molecules such as IL-1 $\beta$, IL-6, IL-8, tumor necrosis factor alpha (TNF- $\alpha$ ) as well as inducible nitric oxide synthase (iNOS), which typically trigger Th1 $\mathrm{T}$ cell responses (Wuttge et al., 2001; Yan and Hansson, 2007; Krausgruber et al., 2011). On the other hand, M2 macrophages stimulated by IL-4 (M2a), immune complexes (M2b), or IL-10/IL-13 (M2c) are characterized by increased expression of antiinflammatory molecules including IL-10, arginase-1 (Arg1), mannose receptor, tumor growth factor beta (TGF- $\beta$ ), which are likely to play an antiatherosclerotic role (Wilson, 2010). While both types of macrophages have been identified in atherosclerotic lesions (Bouhlel et al., 2007) and exhibit low expression of $\mathrm{HO}-1$, it has been reported that increased HO-1 expression may contribute to a M2 macrophage activation profile, which is involved in the resolution of inflammation (Weis et al., 2009). Furthermore, different macrophage subtypes have been recently described where expression of $\mathrm{HO}-1$ may play a characteristic role, either as a part of their phenotypic traits or in the modulation of their potential role in lesion formation.

Treatment of macrophages with oxPAPC led to a phenotypic switch of both M1 and M2 phenotypes into a new subtype named as Mox, characterized by exclusive upregulation of redoxregulated genes such as HO-1, sulforedoxin-1 (Srxn1), glutamatecysteine ligase, modifier subunit (Gclm), glutamate-cysteine ligase, catalytic subunit (Gclc), thioredoxin reductase (Txnrd) 1, but also vascular endothelial growth factor (VEGF), nuclear receptor Nr4A2 (Nurr1) and Trb3 (Kadl et al., 2010). Approximately $30 \%$ of macrophages present in atherosclerotic lesions developed by $\mathrm{LDLR}^{-1-}$ mice had this phenotype. Interestingly, polarization into a Mox phenotype was Nrf2 dependent and also characterized by a decreased phagocytic activity (Kadl et al., 2010), which raises the question whether this macrophage could exert proatherosclerotic actions, despite its high expression of $\mathrm{HO}$ 1 and other antioxidant genes (Araujo, 2012). More recently, another subtype of macrophages has been described in association with intraplaque hemorrhage named as Mhem, characterized 


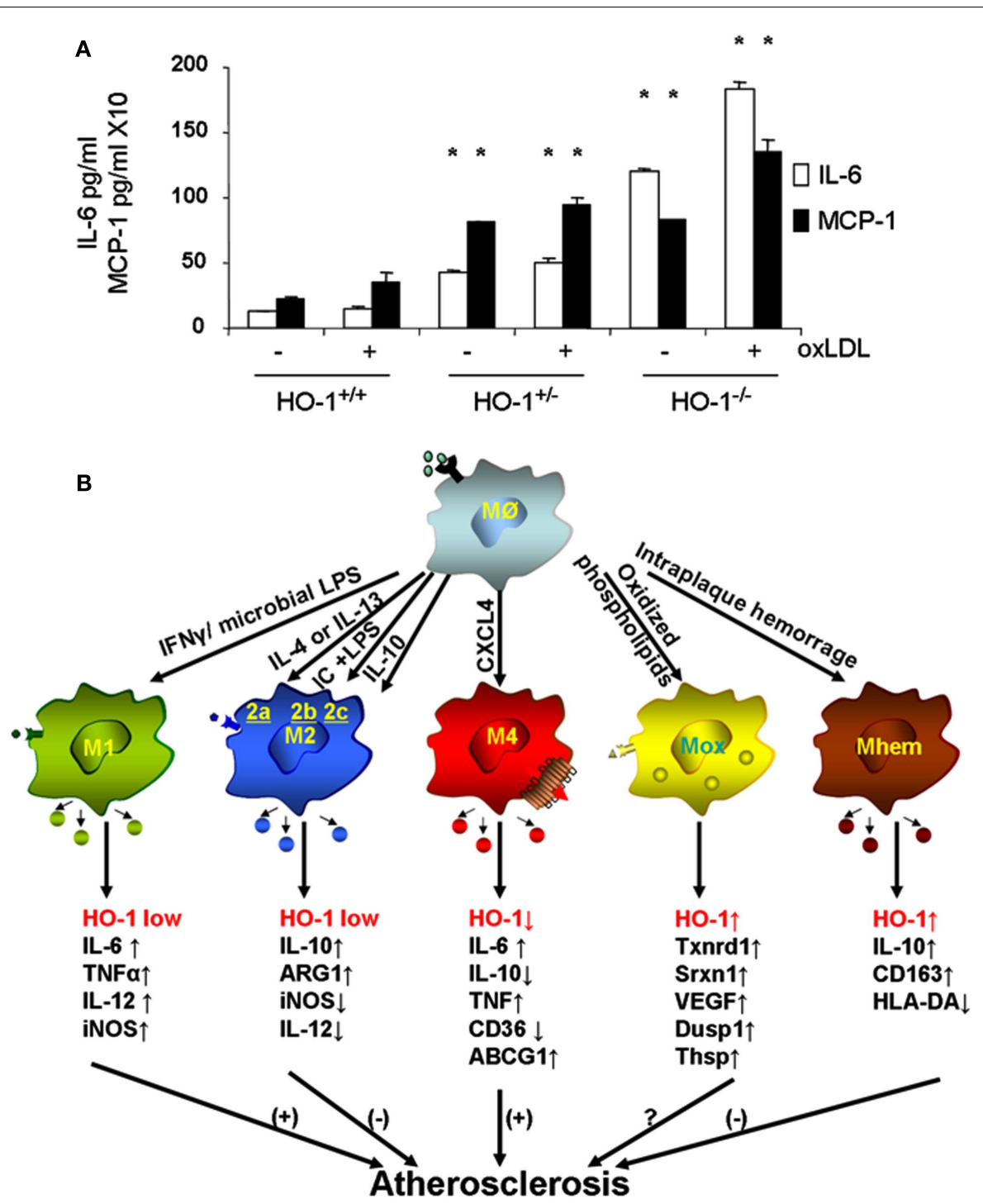

FIGURE 5 | Heme oxygenase-1 inhibits macrophage

proinflammatory activity. (A) Peritoneal macrophages from $\mathrm{HO}-1^{+/+}$, $\mathrm{HO}-1^{+/-}$, and $\mathrm{HO}-1^{+/+}$mice were cultured in the presence or absence of oxLDL $50 \mu \mathrm{g} / \mathrm{ml}$ for $6 \mathrm{~h}$. IL-6 and MCP-1 were determined by ELISA. ${ }^{*} p<0.001$ as compared with controls. Data taken from Orozco et al. (2007). (B) HO-1 expression varies in different subtypes of macrophages. Upon monocyte differentiation into macrophages, they can polarize into one of the five proposed subtypes, M1, M2, M4, Mox, and Mhem. Each subtype is induced by specific stimuli as shown along the arrows that derive from the macrophage Mø atop, and characterized by a set of phenotypic markers and/or gene expression shown below each one of them. While some of macrophage subtypes are proposed to simulate atherogenesis such as $\mathrm{M} 1$ and $\mathrm{M} 4$, others are proposed to inhibit lesion development such as M2 and Mhem. Mox macrophages, generated after treatment with oxPAPC, are dependent on Nrf2 with a role in atherogenesis still to be determined. by increased expression of IL-10 and CD163, macrophage scavenge receptor for hemoglobin-haptoglobin complex ( $\mathrm{Hb}-\mathrm{Hp})$, low expression of human leukocyte antigen-DR (HLA-DR; Boyle et al., 2009). Mhem macrophages also exhibit increased expression of HO-1, dependent on Nrf2 (Boyle et al., 2011) in addition to activating transcription factor 1 (Boyle et al., 2012). These macrophages could play an antiatherogenic role by virtue of its participation in $\mathrm{Hb}-\mathrm{Hp}$ clearance, with subsequent reduction in ROS formation and antiinflammatory effects. One last macrophage subtype named M4 is induced by CXCL4 and characterized by a gene expression profile that contained both M1 and M2 genes (Gleissner et al., 2010). Unlike Mhem macrophages which have increased expression of CD163 (also known as ED2) and $\mathrm{HO}-1, \mathrm{M} 4$ macrophages do not express $\mathrm{Hb}-\mathrm{Hp}$ scavenger receptor CD163 and do not upregulate $\mathrm{HO}-1$ expression (Gleissner, 2012). M4 macrophages appear to play a proatherogenic role, which is consistent with the $\sim 60 \%$ decrease in aortic atherosclerotic lesions exhibited by CXCL- $4^{-1-} \mathrm{ApoE}^{-1-}$ mice (Sachais et al., 2007). It is clear then that macrophage differentiation and polarization is quite complex as they may respond to the very specific microenvironments that monocytes and macrophages encounter. These various macrophage subtypes exhibit different patterns of 
HO-1 expression (Figure 5B) and it is unknown whether HO-1 could play a role in the polarization into any of these subtypes or in the function that these macrophages could have in atherogenesis. For instance, Nrf2 expression appears to be essential in the generation of Mox macrophages and participate in the generation of Mhem macrophages as well, both of which express high levels of HO-1 but perhaps with different roles in the development of atherosclerotic lesions. Thus, the role for HO-1 expression in these various macrophage subtypes still need to be determined (Figure 5B).

\section{SMOOTH MUSCLE CELLS}

Heme oxygenase- 1 is also expressed in vascular SMCs and could play an important role in the protection against atherogenesis. This is supported by evidence accrued in the model of post-angioplasty restenosis where the proliferative response of SMCs constitutes a fundamental aspect of the disease (Duckers et al., 2001; Tulis et al., 2001). SMC proliferative response has been shown to be important in the progression of atherosclerotic plaques as well. On the other hand, SMC and their synthesis of collagen are important contributors to plaque composition and stability as thicker fibrous caps are associated with lesser vulnerability for rupture. As mentioned above, inhibition of $\mathrm{HO}$ activity by ZnPPIX decreased relative cap thickness and intimal surface of SMC in ApoE null mice (Cheng et al., 2009). Likewise, administration of SnPPIX to rabbits resulted in plaques with decreased content of SMC while hemin led to the opposite (Li et al., 2011). Whether these effects are due to HO-1 expression in SMC per se or due its expression in neighboring cells is not clear.

In summary, the overall antiatherogenic role of HO-1 expression may be due to a combination of complex systemic and vascular local effects that converge in the inhibition of lipid peroxidation with effects on circulating lipoproteins, decrease in the activation of endothelial cells, inhibition of macrophage proinflammatory activity and possible participation in its differentiation/polarization, inhibition of dendritic cell maturation as well as modulation of immune-mediated responses and regulation of the proliferative response of SMCs.

\section{HEME OXYGENASE SYSTEM, ENZYMATIC BYPRODUCTS, AND PROTECTION AGAINST ATHEROSCLEROSIS}

Heme oxygenase- 1 is not only expressed ubiquitously in the body but it is also located in several compartments within the cell. It is a $32-\mathrm{kDa}$ protein most abundantly located in the microsomal fraction, with a short transmembrane segment of $\sim 2 \mathrm{kDa}$ in the endoplasmic reticulum membrane and $\sim 30 \mathrm{kDa}$ cytosolic portion. However, HO-1 can also be found in the plasma membrane, associated with caveolae (Kim et al., 2004), in the mitochondria (Converso et al., 2006) and in the nucleus (Lin et al., 2007, 2008). Interestingly, while nuclear HO-1 was shown to be catalytically inactive (Lin et al., 2008), it appeared to modulate the expression of itself (Lin et al., 2008) and that of activating protein (AP)-1 (Lin et al., 2007). Although HO-1 does not have DNA binding domains in its sequence and no definite protein-protein interactions have been demonstrated, additional work is required to elucidate whether HO-1 may play a role in transcriptional regulation. It appears that the biological effects due to HO- 1 expression are mostly due to its enzymatic activity, since its pharmacological inhibition results in almost complete abolishment of those biological effects. Therefore, the various byproducts of HO enzymatic activity could be considered as its "branches" or "arms of action."

\section{BILIVERDIN/BILIRUBIN}

There is evidence that biliverdin/bilirubin can mediate some of HO-1 antiatherogenic effects. Exogenous administration of biliverdin, which is promptly converted to bilirubin, appears to be effective in inhibiting atherogenesis in ApoE null mice (personal communication from Miguel Soares, Gulbenkian Institute of Sciences, Portugal). This parallels the protective effects of biliverdin and/or bilirubin in other models of vascular inflammation, such as liver ischemia reperfusion injury (Fondevila et al., 2004), cardiac allograft graft rejection (Yamashita et al., 2004), and post-angioplasty restenosis (Ollinger et al., 2005, 2007). In addition, epidemiological studies show an inverse relationship of plasma or serum bilirubin concentrations and the risk of CAD (Schwertner et al., 1994; Schwertner and Vitek, 2008), at a strength that was found to be similar to that of smoking, elevated systolic blood pressure, and low HDL cholesterol (Schwertner et al., 1994; Hopkins et al., 1996; Schwertner, 1998). Serum bilirubin concentrations are inversely correlated with the severity of atherosclerosis in men (Novotny and Vitek, 2003). Thus, individuals with Gilbert syndrome, characterized by increased levels of circulating unconjugated bilirubin due to a low reactivity of the bilirubin-uridine diphosphate glucuronyl transferase (bilirubin-UGT) enzyme, exhibit a marked reduction in CHD risk (Schwertner and Vitek, 2008).

Biliverdin/Biliribin could inhibit atherogenesis through to its antioxidant properties. Biliverdin's antioxidant properties appear to depend on the expression of BVR (Singleton and Laster, 1965) and its conversion to bilirubin. Indeed, bilirubin is a powerful antioxidant (Stocker et al., 1987; Stocker and Keaney, 2004) that could inhibit the oxidation of LDL and other lipids (Neuzil and Stocker, 1994; Wu et al., 1996), scavenge oxygen radicals (Stocker et al., 1987) and counteract oxidative stress overall (Schwertner, 1998). The production of bilirubin could participate in an amplification cycle by getting oxidized into biliverdin and then reduced back into bilirubin by BVR (Baranano et al., 2002).

Bilirubin also exerts antiinflammatory and antiproliferative actions that can account for its antiatherogenic effects. Indeed, congenitally hperbilirubinemic Gunn rats exhibit almost no neointimal proliferation after balloon injury in comparison with significant proliferation observed in WT rat controls (Ollinger et al., 2005). Likewise, 1-h local treatment of a rat carotid artery with biliverdin significantly reduces neointima formation after balloon injury (Ollinger et al., 2007). These effects were mediated by inhibition of cell cycle progression and proliferation of SMC (Ollinger et al., 2005, 2007), which could protect against atherosclerosis (Sriram and Patterson, 2001). Various mechanisms may explain antiproliferative effects of Biliverdin/Bilirubin such as: (1) Overexpression of cdk inhibitor p53 resulting in increased apoptosis of rat SMCs (Liu et al., 2002), (2) Inhibition of cyclin A, D1 and E, YY1 and cdk 2 expression, leading to hypophosphorylation of the retinoblastoma tumor suppressor protein $(\mathrm{Rb})$ and 
cell cycle arrest (Ollinger et al., 2005), (3) Inhibition of JNK activation (Ollinger et al., 2007), and (4) Modulation of p38 MAPK activation (Ollinger et al., 2005). Interestingly, bilirubin/biliverdin have been shown to be ligands of the aryl hydrocarbon receptor (Ahr) in mouse hepatoma hepa 1c1c7 cells (Sinal and Bend, 1997; Phelan et al., 1998) and SMCs from Ahr KO mouse aortas exhibit a prolonged cell cycle time as compared with controls (Ollinger et al., 2007), which suggest that Ahr activation could participate in the regulation of proliferation of SMCs. In support of this possibility, Ahr null mice exhibit decreased atherosclerosis in the ApoE null background (Wu et al., 2011).

All this evidence, together with the findings that relate the participation of BVR in insulin-induced pathways (LernerMarmarosh et al., 2005; Kapitulnik and Maines, 2009), make this arm attractive candidate for pharmacological intervention. Thus, development of compounds that either increase the endogenous levels of biliverdin/bilirubin by targeting genes involved in the metabolism or resemble their biological activity can lead to promising new therapies.

\section{CARBON MONOXIDE}

The generation of CO constitutes the second arm how HO-1 may prevent atherosclerosis. In fact, administration of $\mathrm{CO}$ by inhalation results in suppression of intimal hyperplasia associated with chronic graft rejection and balloon injury (Otterbein et al., 2003). Although there are no reports yet about CO inhibitory effects on atherosclerotic lesions due to hyperlipidemia, there are several lines of evidence and potential mechanisms that make it very likely. First, $\mathrm{CO}$ exhibits cytoprotective properties in vascular endothelial cells by inhibiting apoptosis, likely through activation of p38 mitogen-activated protein kinase (MAPK) signaling pathway (Brouard et al., 2000). Second, CO exerts antiinflammatory effects. Indeed, $\mathrm{CO}$ has been shown to modulate the response of monocytes/macrophages to bacterial LPS (Otterbein et al., 2000), decrease macrophage toll-like receptor (TLR) signaling with downstream activation of NF-kB (Wang et al., 2009) and inhibit expression of GM-CSF with probable alteration of macrophage differentiation (Sarady et al., 2002). Inhalation of CO leads to decreased leukocyte infiltration of rat aortic allografts (Otterbein et al., 2003), accompanied by decreased expression of proinflammatory genes associated with macrophage activation (Otterbein et al., 2000). Interestingly, antiinflammatory effects are also mediated by activation of the MAPK signaling pathway, but they appear to require the generation of ROS as inhibition of ROS in macrophages leads to loss of $\mathrm{CO}$ antiinflammatory effects (Bilban et al., 2008). Third, HO-1 and CO may crosstalk with Nitric Oxide Synthases (NOS) and NO. Administration of hemin to rabbits resulted in greater $\mathrm{CO}$ levels in the aorta, accompanied by decreased levels of aortic NO and inducible Nitric oxide synthase (iNOS; Li et al., 2011), while HO inhibition by SnPPIX or ZnPPIX resulted in the opposite (Li et al., 2011; Liu et al., 2012). CO might bind and activate guanylate cyclase, leading to increased intracellular levels of cyclic guanine monophosphate (cGMP; Morita et al., 1995; Hartsfield, 2002). However, the end result in this crosstalk between $\mathrm{CO}$ and $\mathrm{NO}$ may depend on their relative concentrations as both gaseous molecules compete for the same enzyme but with different affinities. In addition, the biological effects due to this interplay between $\mathrm{CO}$ and NO may be characteristic of each cell type. Fourth, CO displays antiproliferative actions in SMCs (Morita et al., 1997), which could account for a good portion of its beneficial effects in the model of balloon injury (Otterbein et al., 2003). These CO effects require activation of p38 MAPK pathway, which appears to occur via a cGMP-dependent mechanism and require activation of guanylate cyclase as well (Otterbein et al., 2003). Last, there is a possibility that $\mathrm{CO}$ could exert antioxidant effects via binding of the $\mathrm{Fe}^{2+}$ in heme groups and preventing the oxidation of hemoproteins, subsequently inhibiting the release of free heme (Balla et al., 1993). This mechanism appears to be important in the suppression of experimental cerebral malaria by CO (Pamplona et al., 2007).

\section{HEME CATABOLISM AND RELEASE OF IRON}

A third arm of action of the HO-1 system with antioxidant effects consists in the catabolic processing of heme groups, including the release and safe disposal of ferrous iron $\left(\mathrm{Fe}^{2+}\right)$. Heme groups, derived from hemoglobin and other hemoproteins, can exacerbate the generation of ROS and membrane lipid peroxidation via the participation of $\mathrm{Fe}^{2+}$ in the Fenton reaction (Ryter and Tyrrell, 2000). Heme groups consist of a central iron atom in a coordinated binding to a protoporphyrin, composed of four pyrrole rings. The oxidative cleavage of this tetrapyrrolic ring leads to the release of its central $\mathrm{Fe}^{2+}$ with the potential of facilitating its participation in redox chemistry. This is how in certain circumstances, overexpression of $\mathrm{HO}$, either $\mathrm{HO}-1$ or $\mathrm{HO}-2$ have been shown to exert prooxidant effects instead (Lamb et al., 1999; Ryter and Tyrrell, 2000). However, the simultaneous expression of ferritin, an important multimeric protein complex with a high capacity for iron storage, helps to channel the safe disposal for $\mathrm{Fe}^{2+}$. In addition, it appears that several of the same stimuli that trigger $\mathrm{HO}-1$ upregulation also increase ferritin expression, at the same time that labile Fe per se can upregulate the expression of heavy-chain (H-) ferritin, which in association with light-chain (L-) ferritin subunits lead to the assembly of ferritin protein (Harrison and Arosio, 1996). Indeed, ferritin expression colocalizes with HO-1 expression in atherosclerotic lesions and in common with $\mathrm{HO}$ 1 , ferritin is markedly increased in various cell types present in atherosclerotic plaques such as myofibroblasts, macrophages, and endothelial cells, where it may play a protective role against oxidized lipoproteins (Juckett et al., 1995). Coordinate expression of HO-1 and ferritin can lead to antioxidant effects by different mechanisms. First, it decreases the bioavailability of $\mathrm{Fe}^{2+}$ to participate in redox chemistry. Second, the ferroxidase activity of the $\mathrm{H}$-chain subunit, leads to the conversion of $\mathrm{Fe}^{2+}$ to $\mathrm{Fe}^{3+}$ and therefore, decrease in iron prooxidant potential (Balla et al., 1992; Berberat et al., 2003). Third, multimeric ferritin can bind free heme with subsequent reduction in its bioavailability (Kadir and Moore, 1990). The prooxidative effects of HO-1 overexpression could be seen when increases in HO-1 levels overwhelm concurrent expression of ferritin. It seems, however, that these potentially deleterious effects that are noted in experimental studies are less likely to occur in normal physiological conditions. Instead, coexpression of both $\mathrm{HO}$ and ferritin appears to play a significant antioxidant role. 
Overall, it appears that all $\mathrm{HO}$ byproducts could contribute to the HO-1 antiatherogenic effects. It remains to be elucidated whether these actions are complementary or merely overlapping and what is the degree of contribution of each one of these arms of action in the HO-1 global effects.

\section{SUMMARY AND PERSPECTIVES}

The overall importance of $\mathrm{HO}$ is underlined by its large degree of evolutionary conservation in all kingdoms of life as it is expressed in prokaryotic and eukaryotic cells, bacteria, yeasts, protozoa, plants, invertebrate and vertebrate animals. In all these various living organisms, $\mathrm{HO}$ contributes to the catabolic processing of hemoproteins and avoidance of the potential toxicity that could be associated to the release of $\mathrm{Fe}$ atoms present on them.

Heme oxygenase appears to exert most of its actions thanks to its enzymatic activity and the generation of various enzymatic byproducts that act on a multiplicity of pathways. Therefore, $\mathrm{HO}$ activity can be visualized as a $\mathrm{HO}$ system with three branches or arms of action that consist in: (1) generation of Biliverdin and subsequent reduction to bilirubin, (2) release of $\mathrm{CO}$, and (3) release and safe disposal of $\mathrm{Fe}^{2+}$. These arms of action modulate various pathways with a high degree of overlap and/or cross-over, which may help to ensure the induction of the desired biological effects. HO-1 is most abundant in the cytosol, attached to the smooth endoplasmic reticulum (SER) membrane. However, its presence in other subcellular localizations such as the plasma membrane, mitochondria, or nucleus raises the question whether HO could exert some protein-protein or protein-DNA interactions that could play other roles, such as transcriptional regulation, which requires further exploration. HO- 1 and the $\mathrm{HO}$ system in general are thought to play a critical role in cellular homeostasis where the presence of complementarity or overlap between the arms of action could result in some degree of redundancy that can help to ensure the induction of $\mathrm{HO}$ mediated critical effects. These principles are also seen in the protection against vascular inflammation and atherosclerosis. Thus, HO three arms of action have various degrees of antioxidant, antiinflammatory, antiapoptotic, antiproliferative, and immunomodulatory effects, most of which may play a significant role in the protection against atherosclerotic lesion formation.

Heme oxygenase-1 has been shown to be a critical gene in the cellular response against prooxidative stimuli such as oxidized phospholipids. When considering the cellular response as a whole, HO- 1 acts as a hub of gene-gene interactions that modulate the triggering and activation of several protective molecular pathways.

\section{REFERENCES}

Abraham, N. G., and Kappas, A. (2008). Pharmacological and clinical aspects of heme oxygenase. Pharmacol. Rev. 60, 79-127.

Amersi, F., Buelow, R., Kato, H., Ke, B., Coito, A. J., Shen, X. D., Zhao, D., Zaky, J., Melinek, J., Lassman, C. R., Kolls, J. K., Alam, J., Ritter, T., Volk, H. D., Farmer, D. G., Ghobrial, R. M., Busuttil, R. W., and KupiecWeglinski, J. W. (1999). Upregulation of heme oxygenase- 1 protects

This has been demonstrated in endothelial cells and is likely to be the case in other vascular cells such as monoctyes/macrophages. In addition, HO-1 may be a protective gene against proatherogenic effects caused by environmental factors such as cigarette smoking or exposure to air pollution.

Basal HO-1 mRNA expression levels in response to injurious stimuli appear to be more important than the degree of upregulation or fold induction for the protection against those stimuli in the vasculature. In some circumstances, the levels of $\mathrm{HO}-1$ protein and $\mathrm{HO}$ functional activity may not be concordant which could be due to posttranslational modifications. Therefore, a better understanding of their kinetics in vascular processes such as atherosclerosis is required to shed light on the reasons why very high levels of upregulated HO-1 in vascular cells may be overwhelmed by the pathogenic process and fail to abrogate the progression of atherosclerotic lesions. Importantly, $\mathrm{HO}-1$ can be targeted pharmacologically by interventions that seek its upregulation or enhancement of its various arms of action, via: (1) induction of HO-1 expression with drugs such as heme arginate, (2) administration of $\mathrm{CO}$ by inhalation or use of CO releasing molecules (CORM), and (3) administration of biliverdin/bilirubin or use of inhibitors of bilirubin conjugation that would result in increased bilirubin levels.

One potential caveat, however, is that modulation of $\mathrm{HO}-1$ could result in alteration of the activation status of its transcription factor Nrf2, which has been shown to exert proatherosclerotic effects. The discordant effects between Nrf2 and HO-1 underline the high degree of complexity that therapeutic modulation of vascular oxidative stress must address. This is in addition to studies that have shown that while some oxidation products promote inflammation in the vascular wall, others could have antiinflammatory activity instead. Indeed, electrophilic nitro-fatty acids which are formed via nitric oxide or nitrite-dependent redox reactions have been shown to exert antiinflammatory actions (Khoo and Freeman, 2010). Therefore, any pharmacological modulation of HO- 1 should take into consideration any potential alteration of the Nrf2 activation status.

\section{ACKNOWLEDGMENTS}

Writing of this article was supported by the National Institute of Environmental Health Sciences, National Institutes of Health (RO1 Award ES016959 to Jesus A. Araujo). We are grateful to Luz Orozco for providing Figure 5A and to Casey Romanoski and Aldons Lusis for providing Figure 3.

Araujo, J. A. (2012). Nrf2 and the promotion of atherosclerosis: lessons to be learned. Clin. Lipidol. 7, 123-116. Araujo, J. A., Meng, L., Tward, A. D., Hancock, W. W., Zhai, Y., Lee, A., Ishikawa, K., Iyer, S., Buelow, R., Busuttil, R. W., Shih, D. M., Lusis, A. J., and Kupiec-Weglinski, J. W. (2003). Systemic rather than local heme oxygenase-1 overexpression improves cardiac allograft outcomes in a new transgenic mouse. $J$. Immunol. 171, 1572-1580.
Balla, G., Jacob, H. S., Balla, J., Rosenberg, M., Nath, K., Apple, F., Eaton, J. W., and Vercellotti, G. M. (1992). Ferritin: a cytoprotective antioxidant strategem of endothelium. J. Biol. Chem. 267, 18148-18153.

Balla, G., Jacob, H. S., Eaton, J. W., Belcher, J. D., and Vercellotti, G. M. (1991). Hemin: a possible physiological mediator of low density lipoprotein oxidation and endothelial injury. Arterioscler. Thromb. Vasc. Biol. 11, 1700-1711. 
Balla, J., Jacob, H. S., Balla, G., Nath, K., Eaton, J. W., and Vercellotti, G. M. (1993). Endothelial-cell heme uptake from heme proteins: induction of sensitization and desensitization to oxidant damage. Proc. Natl. Acad. Sci. U.S.A. 90, 9285-9289.

Barajas, B., Che, N., Yin, F., Rowshanrad, A., Orozco, L. D., Gong, K. W., Wang, X., Castellani, L. W., Reue, K., Lusis, A. J., and Araujo, J. A. (2011). NF-E2related factor 2 promotes atherosclerosis by effects on plasma lipoproteins and cholesterol transport that overshadow antioxidant protection. Arterioscler. Thromb. Vasc. Biol. 31, 58-66.

Baranano, D. E., Rao, M., Ferris, C. D., and Snyder, S. H. (2002). Biliverdin reductase: a major physiologic cytoprotectant. Proc. Natl. Acad. Sci. U.S.A. 99, 16093-16098.

Barry-Lane, P. A., Patterson, C., Van Der Merwe, M., Hu, Z., Holland, S. M., Yeh, E. T., and Runge, M. S. (2001). p47phox is required for atherosclerotic lesion progression in $\mathrm{ApoE}(-/-)$ mice. J. Clin. Invest. 108, 1513-1522.

Berberat, P. O., Katori, M., Kaczmarek, E., Anselmo, D., Lassman, C., Ke, B., Shen, X., Busuttil, R. W., Yamashita, K., Csizmadia, E., Tyagi, S., Otterbein, L. E., Brouard, S., Tobiasch, E., Bach, F. H., Kupiec-Weglinski, J. W., and Soares, M. P. (2003). Heavy chain ferritin acts as an antiapoptotic gene that protects livers from ischemia reperfusion injury. FASEB J. 17, 1724-1726.

Bilban, M., Haschemi, A., Wegiel, B., Chin, B. Y., Wagner, O., and Otterbein, L. E. (2008). Heme oxygenase and carbon monoxide initiate homeostatic signaling. J. Mol. Med. 86, 267-279.

Bobryshev, Y. V. (2005). Dendritic cells in atherosclerosis: current status of the problem and clinical relevance. Eur. Heart J. 26, 1700-1704.

Bobryshev, Y. V. (2010). Dendritic cells and their role in atherogenesis. Lab. Investig. 90, 970-984.

Bouhlel, M. A., Derudas, B., Rigamonti, E., Dievart, R., Brozek, J., Haulon, S., Zawadzki, C., Jude, B., Torpier, G., Marx, N., Staels, B., and ChinettiGbaguidi, G. (2007). PPAR gamma activation primes human monocytes into alternative M2 macrophages with anti-inflammatory properties. Cell Metab. 6, 137-143.

Boyle, J. J., Harrington, H. A., Piper, E., Elderfield, K., Stark, J., Landis, R. C., and Haskard, D. O. (2009). Coronary intraplaque hemorrhage evokes a novel atheroprotective macrophage phenotype. Am. J. Pathol. 174, 1097-1108.
Boyle, J. J., Johns, M., Kampfer, T., Nguyen, A. T., Game, L., Schaer, D. J., Mason, J. C., and Haskard, D. O. (2012). Activating transcription factor 1 directs mhem atheroprotective macrophages through coordinated iron handling and foam cell protection. Circ. Res. 110, 20-33.

Boyle, J. J., Johns, M., Lo, J., Chiodini, A., Ambrose, N., Evans, P. C., Mason, J. C., and Haskard, D. O. (2011). Heme induces heme oxygenase 1 via Nrf2 role in the homeostatic macrophage response to intraplaque hemorrhage. Arterioscler. Thromb. Vasc. Biol. 31, U2685-U2826.

Brasen, J. H., Leppanen, O., Inkala, M., Heikura, T., Levin, M., Ahrens, F., Rutanen, J., Pietsch, H., Bergqvist, D., Levonen, A. L., Basu, S., Zeller, T., Kloppel, G., Laukkanen, M. O., and Yla-Herttuala, S. (2007). Extracellular superoxide dismutase accelerates endothelial recovery and inhibits instent restenosis in stented atherosclerotic Watanabe heritable hyperlipidemic rabbit aorta. J. Am. Coll. Cardiol. 50, 2249-2253.

Brouard, S., Otterbein, L. E., Anrather, J., Tobiasch, E., Bach, F. H., Choi, A. M., and Soares, M. P. (2000). Carbon monoxide generated by heme oxygenase 1 suppresses endothelial cell apoptosis. J. Exp. Med. 192, 1015-1026.

Burns, M. J., and Furie, M. B. (1998). Borrelia burgdorferi and interleukin-1 promote the transendothelial migration of monocytes in vitro by different mechanisms. Infect. Immun. 66, 4875-4883.

Callegari, A., Liu, Y., White, C. C., Chait, A., Gough, P., Raines, E. W., Cox, D., Kavanagh, T. J., and Rosenfeld, M. E. (2011). Gain and loss of function for glutathione synthesis: impact on advanced atherosclerosis in apolipoprotein E-deficient mice. Arterioscler. Thromb. Vasc. Biol. 31, 2473-2482.

Chauveau, C., Remy, S., Royer, P. J., Hill, M., Tanguy-Royer, S., Hubert, F. X., Tesson, L., Brion, R., Beriou, G., Gregoire, M., Josien, R., Cuturi, M. C., and Anegon, I. (2005). Heme oxygenase-1 expression inhibits dendritic cell maturation and proinflammatory function but conserves IL-10 expression. Blood 106, 1694-1702.

Chen, Y. H., Chau, L. Y., Lin, M. W., Chen, L. C., Yo, M. H., Chen, J. W., and Lin, S. J. (2004). Heme oxygenase-1 gene promotor microsatellite polymorphism is associated with angiographic restenosis after coronary stenting. Eur. Heart J. 25, 39-47.

Chen, Y. H., Lin, S. J., Lin, M. W. Tsai, H. L., Kuo, S. S., Chen, J. W., Charng, M. J., Wu, T. C., Chen, L. C., Ding, Y. A., Pan, W. H., Jou, Y. S. and Chau, L.Y. (2002). Microsatellite polymorphism in promoter of heme oxygenase- 1 gene is associated with susceptibility to coronary artery disease in type 2 diabetic patients. Hum. Genet. 111, 1-8.

Cheng, C., Noordeloos, A. M., Jeney, V., Soares, M. P., Moll, F., Pasterkamp, G., Serruys, P. W., and Duckers, H. J. (2009). Heme oxygenase 1 determines atherosclerotic lesion progression into a vulnerable plaque. Circulation 119, 3017-3027.

Choi, A. M., and Alam, J. (1996). Heme oxygenase-1: function, regulation, and implication of a novel stress-inducible protein in oxidantinduced lung injury. Am. J. Respir. Cell Mol. Biol. 15, 9-19.

Coito, A. J., Buelow, R., Shen, X. D., Amersi, F., Moore, C., Volk, H. D., Busuttil, R. W., and KupiecWeglinski, J. W. (2002). Heme oxygenase-1 gene transfer inhibits inducible nitric oxide synthase expression and protects genetically fat Zucker rat livers from ischemiareperfusion injury. Transplantation 74, 96-102.

Converso, D. P., Taille, C., Carreras, M. C., Jaitovich, A., Poderoso, J. J., and Boczkowski, J. (2006). HO-1 is located in liver mitochondria and modulates mitochondrial heme content and metabolism. FASEB J. 20 1236-1238.

Duckers, H. J., Boehm, M., True, A. L., Yet, S. F., San, H., Park, J. L., Clinton Webb, R., Lee, M. E., Nabel, G. J., and Nabel, E. G. (2001). Heme oxygenase-1 protects against vascular constriction and proliferation. Nat. Med. 7, 693-698.

Durand, E., Al Haj Zen, A., Addad, F., Brasselet, C., Caligiuri, G., Vinchon, F., Lemarchand, P., Desnos, M. Bruneval, P., and Lafont, A. (2005). Adenovirus-mediated gene transfer of superoxide dismutase and catalase decreases restenosis after balloon angioplasty. J. Vasc. Res. 42 , 255-265.

Durante, W. (2011). Protective role of heme oxygenase-1 against inflammation in atherosclerosis. Front. Biosci. 16 2372-2388

Exner, M., Schillinger, M., Minar, E., Mlekusch, W., Schlerka, G., Haumer, M., Mannhalter, C., and Wagner, O. (2001). Heme oxygenase-1 gene promoter microsatellite polymorphism is associated with restenosis after percutaneous transluminal angioplasty. J. Endovasc. Ther. 8, 433-440. Fondevila, C., Shen, X. D., Tsuchiyashi, S., Yamashita, K., Csizmadia, E., Lassman, C., Busuttil, R. W., KupiecWeglinski, J. W., and Bach, F. H. (2004). Biliverdin therapy protects rat livers from ischemia and reperfusion injury. Hepatology 40, 1333-1341.

Freigang, S., Ampenberger, F., Spohn, G., Heer, S., Shamshiev, A. T., Kisielow, J., Hersberger, M., Yamamoto, M., Bachmann, M. F., and Kopf, M. (2011). Nrf2 is essential for cholesterol crystalinduced inflammasome activation and exacerbation of atherosclerosis. Eur. J. Immunol. 41, 2040-2051.

Gleissner, C. A. (2012). Macrophage phenotype modulation by CXCL4 in atherosclerosis. Front. Physiol. 3:1. doi:10.3389/fphys.2012.00001

Gleissner, C. A., Shaked, I., Little, K. M., and Ley, K. (2010). CXC chemokine ligand 4 induces a unique transcriptome in monocytederived macrophages. J. Immunol. 184, 4810-4818.

Gong, K. W., Zhao, W., Li, N., Barajas, B., Kleinman, M., Sioutas, C., Horvath, S., Lusis, A. J., Nel, A., and Araujo, J. A. (2007). Air-pollutant chemicals and oxidized lipids exhibit genome-wide synergistic effects on endothelial cells. Genome Biol. 8 , R149.

Hancock, W. W., Buelow, R., Sayegh, M. H., and Turka, L. A. (1998). Antibody-induced transplant arteriosclerosis is prevented by graft expression of anti-oxidant and antiapoptotic genes. Nat. Med. 4 1392-1396.

Harrison, P. M., and Arosio, P. (1996). The ferritins: molecular properties, iron storage function and cellular regulation. Biochim. Biophys. Acta 1275, 161-203.

Hartsfield, C. L. (2002). Cross talk between carbon monoxide and nitric oxide. Antioxid. Redox Signal. 4,301-307.

Hayashi, S., Omata, Y., Sakamoto, H., Higashimoto, Y., Hara, T., Sagara, Y., and Noguchi, M. (2004). Characterization of rat heme oxygenase- 3 gene. Implication of processed pseudogenes derived from heme oxygenase2 gene. Gene 336, 241-250.

Hopkins, P. N., Wu, L. L., Hunt, S. C., James, B. C., Vincent, G. M., and Williams, R. R. (1996). Higher serum bilirubin is associated with decreased risk for early familial coronary artery disease. Arterioscler. Thromb. Vasc. Biol. 16, 250-255. 
Huang, J., Tabbi-Anneni, I., Gunda, V., and Wang, L. (2010). Transcription factor Nrf2 regulates SHP and lipogenic gene expression in hepatic lipid metabolism. Am. J. Physiol. Gastrointest. Liver Physiol. 299, G1211-G1221.

Ishii, T., Itoh, K., Ruiz, E., Leake, D. S., Unoki, H., Yamamoto, M., and Mann, G. E. (2004). Role of $\mathrm{Nrf} 2$ in the regulation of CD36 and stress protein expression in murine macrophages: activation by oxidatively modified LDL and 4-hydroxynonenal. Circ. Res. 94, 609-616.

Ishikawa, K., Navab, M., and Lusis, A. J. (2012). Vascultiis, atherosclerosis, and altered HDL composition in heme-oxygenase-1-knockout mice. Int. J. Hypertens. doi: 10.1155/2012/948203

Ishikawa, K., Sugawara, D., Goto, J., Watanabe, Y., Kawamura, K., Shiomi, M., Itabe, H., and Maruyama, Y. (2001a). Heme oxygenase-1 inhibits atherogenesis in Watanabe heritable hyperlipidemic rabbits. Circulation 104, 1831-1836.

Ishikawa, K., Sugawara, D., Wang, X., Suzuki, K., Itabe, H., Maruyama, Y., and Lusis, A. J. (2001b). Heme oxygenase-1 inhibits atherosclerotic lesion formation in ldlreceptor knockout mice. Circ. Res. 88, 506-512.

Jeney, V., Balla, J., Yachie, A., Varga, Z., Vercellotti, G. M., Eaton, J. W., and Balla, G. (2002). Pro-oxidant and cytotoxic effects of circulating heme. Blood 100, 879-887.

Juan, S. H., Lee, T. S., Tseng, K. W., Liou, J. Y., Shyue, S. K., Wu, K. K., and Chau, L. Y. (2001). Adenovirusmediated heme oxygenase-1 gene transfer inhibits the development of atherosclerosis in apolipoprotein E-deficient mice. Circulation 104, 1519-1525.

Juckett, M. B., Balla, J., Balla, G., Jessurun, J., Jacob, H. S., and Vercellotti, G. M. (1995). Ferritin protects endothelial cells from oxidized low density lipoprotein in vitro. Am. J. Pathol. 147, 782-789.

Kadir, F. H., and Moore, G. R. (1990). Haem binding to horse spleen ferritin. FEBS Lett. 276, 81-84.

Kadl, A., Meher, A. K., Sharma, P. R., Lee, M. Y., Doran, A. C., Johnstone, S. R., Elliott, M. R., Gruber, F., Han, J., Chen, W., Kensler, T., Ravichandran, K. S., Isakson, B. E., Wamhoff, B. R., and Leitinger, N. (2010). Identification of a novel macrophage phenotype that develops in response to atherogenic phospholipids via Nrf2. Circ. Res. 107, 737-746.

Kaneda, H., Ohno, M., Taguchi, J., Togo, M., Hashimoto, H., Ogasawara, K., Aizawa, T., Ishizaka, N., and Nagai, R. (2002). Heme oxygenase-1 gene promoter polymorphism is associated with coronary artery disease in Japanese patients with coronary risk factors. Arterioscler. Thromb. Vasc. Biol. 22, 1680-1685.

Kapitulnik, J., and Maines, M. D. (2009). Pleiotropic functions of biliverdin reductase: cellular signaling and generation of cytoprotective and cytotoxic bilirubin. Trends Pharmacol. Sci. 30, 129-137.

Kato, H., Amersi, F., Buelow, R., Melinek, J., Coito, A. J., Ke, B., Busuttil, R. W., and Kupiec-Weglinski, J. W. (2001). Heme oxygenase-1 overexpression protects rat livers from ischemia/reperfusion injury with extended cold preservation. Am. J. Transplant. 1, 121-128.

Kawashima, A., Oda, Y., Yachie, A., Koizumi, S., and Nakanishi, I. (2002). Heme oxygenase-1 deficiency: the first autopsy case. Hum. Pathol. 33, 125-130.

Ke, B., Shen, X. D., Melinek, J., Gao, F., Ritter, T., Volk, H. D., Busuttil, R. W., and Kupiec-Weglinski, J. W. (2001). Heme oxygenase-1 gene therapy: a novel immunomodulatory approach in liver allograft recipients? Transplant. Proc. 33, 581-582.

Ke, B. B., Shen, X. D., Melinek, J., Busuttil, R. W., and Kupiec-Weglinski, J. W. (2000). Heme oxygenase-1 gene therapy upregulates $\mathrm{TH} 2$-dependent expression of protective molecules in liver allograft recipents: implications for novel immunomodulatory approach. Transplantation 69, S280.

Khoo, N. K., and Freeman, B. A. (2010) Electrophilic nitro-fatty acids: antiinflammatory mediators in the vascular compartment. Curr. Opin. Pharmacol. 10, 179-184.

Kim, H. P., Wang, X., Galbiati, F., Ryter, S. W., and Choi, A. M. (2004). Caveolae compartmentalization of heme oxygenase-1 in endothelial cells. FASEB J. 18, 1080-1089.

Krausgruber, T., Blazek, K., Smallie, T., Alzabin, S., Lockstone, H., Sahgal, N., Hussell, T., Feldmann, M., and Udalova, I. A. (2011). IRF5 promotes inflammatory macrophage polarization and TH1-TH17 responses. Nat. Immunol. 12, 231-238.

Kruger, A. L., Peterson, S., Turkseven, S., Kaminski, P. M., Zhang, F. F., Quan, S., Wolin, M. S., and Abraham, N. G. (2005). D-4F induces heme oxygenase-1 and extracellular superoxide dismutase, decreases endothelial cell sloughing, and improves vascular reactivity in rat model of diabetes. Circulation 111 , 3126-3134.

Kruger, A. L., Peterson, S. J., Schwartzman, M. L., Fusco, H., Mcclung, J. A., Weiss, M., Shenouda, S., Goodman, A. I., Goligorsky, M. S., Kappas, A., and Abraham, N. G. (2006). Up-regulation of heme oxygenase provides vascular protection in an animal model of diabetes through its antioxidant and antiapoptotic effects. J. Pharmacol. Exp. Ther. 319, 1144-1152.

Lamb, N. J., Quinlan, G. J., Mumby, S., Evans, T. W., and Gutteridge, J. M. (1999). Haem oxygenase shows pro-oxidant activity in microsoma and cellular systems: implications for the release of low-molecularmass iron. Biochem. J. 344( $\mathrm{Pt} \mathrm{1),}$ 153-158.

Laukkanen, M. O., Kivela, A., Rissanen, T., Rutanen, J., Karkkainen, M. K., Leppanen, O., Brasen, J. H., and Yla-Herttuala, S. (2002). Adenovirus-mediated extracellular superoxide dismutase gene therapy reduces neointima formation in balloon-denuded rabbit aorta. Circulation 106, 1999-2003.

Lee, T. S., Tsai, H. L., and Chau, L. Y. (2003). Induction of heme oxygenase-1 expression in murine macrophages is essential for the anti-inflammatory effect of low dose 15-deoxy-Delta(12,14)prostaglandin J(2). J. Biol. Chem. 278, 19325-19330.

Lerner-Marmarosh, N., Shen, J., Torno, M. D., Kravets, A., Hu, Z., and Maines, M. D. (2005). Human biliverdin reductase: a member of the insulin receptor substrate family with serine/threonine/tyrosine kinase activity. Proc. Natl. Acad. Sci. U.S.A. 102, 7109-7114.

Levonen, A. L., Inkala, M., Heikura, T., Jauhiainen, S., Jyrkkanen, H. K., Kansanen, E., Maatta, K., Romppanen, E., Turunen, P., Rutanen, J., and Yla-Herttuala, S. (2007). Nrf2 gene transfer induces antioxidant enzymes and suppresses smooth muscle cell growth in vitro and reduces oxidative stress in rabbit aorta in vivo. Arterioscler. Thromb. Vasc. Biol. 27, 741-747.

Lewis, P., Stefanovic, N., Pete, J., Calkin, A. C., Giunti, S., Thallas-Bonke, V., Jandeleit-Dahm, K. A., Allen, T. J. Kola, I., Cooper, M. E., and De Haan, J. B. (2007). Lack of the antioxidant enzyme glutathione peroxidase-1 accelerates atherosclerosis in diabetic apolipoprotein E-deficient mice. Circulation 115, 2178-2187.
Li, T., Tian, H., Zhao, Y., An, F., Zhang, L., Zhang, J., Peng, J., Zhang, Y., and Guo, Y. (2011). Heme oxygenase-1 inhibits progression and destabilization of vulnerable plaques in a rabbit model of atherosclerosis. Eur. J. Pharmacol. 672, 143-152.

Lin, Q., Weis, S., Yang, G., Weng, Y. H., Helston, R., Rish, K., Smith, A., Bordner, J., Polte, T., Gaunitz, F., and Dennery, P. A. (2007). Heme oxygenase-1 protein localizes to the nucleus and activates transcription factors important in oxidative stress. J. Biol. Chem. 282, 20621-20633.

Lin, Q. S., Weis, S., Yang, G., Zhuang, T., Abate, A., and Dennery, P. A. (2008). Catalytic inactive heme oxygenase-1 protein regulates its own expression in oxidative stress. Free Radic. Biol. Med. 44, 847-855.

Liu, D., He, Z., Wu, L., and Fang, Y. (2012). Effects of induction/ inhibition of endogenous heme oxygenase-1 on lipid metabolism, endothelial function, and atherosclerosis in rabbits on a high fat diet. J. Pharmacol. Sci. 118, 14-24.

Liu, X. M., Chapman, G. B., Wang, H., and Durante, W. (2002). Adenovirus-mediated heme oxygenase-1 gene expression stimulates apoptosis in vascular smooth muscle cells. Circulation 105, 79-84.

Llodra, J., Angeli, V., Liu, J., Trogan, E., Fisher, E. A., and Randolph, G. J. (2004). Emigration of monocytederived cells from atherosclerotic lesions characterizes regressive, but not progressive, plaques. Proc. Natl. Acad. Sci. U.S.A. 101, 11779-11784.

Lusis, A. J. (2000). Atherosclerosis. Nature 407, 233-241.

Maines, M. D. (1997). The heme oxygenase system: a regulator of second messenger gases. Annu. Rev. Pharmacol. Toxicol. 37, 517-554.

Manthey, H., and Zernecke, A. (2011). Dendritic cells in atherosclerosis: functions in immune regulation and beyond. Thromb. Haemost. 106.

Minamino, T., Christou, H., Hsieh, C. M., Liu, Y. X., Dhawan, V., Abraham, N. G., Perrella, M. A., Mitsialis, S. A., and Kourembanas, S. (2001). Targeted expression of heme oxygenase1 prevents the pulmonary inflammatory and vascular responses to hypoxia. Proc. Natl. Acad. Sci. U.S.A. 98, 8798-8803.

Morita, T. (2005). Heme oxygenase and atherosclerosis. Arterioscler. Thromb. Vasc. Biol. 25 1786-1795.

Morita, T., Mitsialis, S. A., Koike, H., Liu, Y., and Kourembanas, S. (1997). Carbon monoxide controls 
the proliferation of hypoxic vascular smooth muscle cells. J. Biol. Chem. 272, 32804-32809.

Morita, T., Perrella, M. A., Lee, M. E., and Kourembanas, S. (1995). Smooth muscle cell-derived carbon monoxide is a regulator of vascular cGMP. Proc. Natl. Acad. Sci. U.S.A. 92, 1475-1479.

Nagy, E. K., Eaton, J. W., Jeney, V. R., Soares, M. P., Varga, Z., Galajda, Z. N., Szentmiklósi, J. Z., Méhes, G. B., Csonka, T. S., Smith, A., Vercellotti, G. M., Balla, G. R., and Balla, J. Z. (2010). Red cells, hemoglobin, heme, iron, and atherogenesis. Arterioscler. Thromb. Vasc. Biol. 30, 1347-1353.

Neuzil, J., and Stocker, R. (1994). Free and albumin-bound bilirubin are efficient co-antioxidants for alpha-tocopherol, inhibiting plasma and low density lipoprotein lipid peroxidation. J. Biol. Chem. 269, 16712-16719.

Novotny, L., and Vitek, L. (2003). Inverse relationship between serum bilirubin and atherosclerosis in men: a meta-analysis of published studies. Exp. Biol. Med. 228, 568-571.

Ollinger, R., Bilban, M., Erat, A., Froio, A., Mcdaid, J., Tyagi, S., Csizmadia, E., Graca-Souza, A. V., Liloia, A., Soares, M. P., Otterbein, L. E., Usheva, A., Yamashita, K., and Bach, F. H. (2005). Bilirubin: a natural inhibitor of vascular smooth muscle cell proliferation. Circulation 112, 1030-1039.

Ollinger, R., Yamashita, K., Bilban, M., Erat, A., Kogler, P., Thomas, M., Csizmadia, E., Usheva, A., Margreiter, R., and Bach, F. H. (2007). Bilirubin and biliverdin treatment of atherosclerotic diseases. Cell Cycle 6, 39-43.

Orozco, L. D., Kapturczak, M. H., Barajas, B., Wang, X., Weinstein, M. M., Wong, J., Deshane, J., Bolisetty, S., Shaposhnik, Z., Shih, D. M., Agarwal, A., Lusis, A. J., and Araujo, J. A. (2007). Heme oxygenase-1 expression in macrophages plays a beneficial role in atherosclerosis. Circ. Res. 100, 1703-1711.

Otterbein, L. E., Bach, F. H., Alam, J., Soares, M., Tao Lu, H., Wysk, M., Davis, R. J., Flavell, R. A., and Choi, A. M. (2000). Carbon monoxide has anti-inflammatory effects involving the mitogen-activated protein kinase pathway. Nat. Med. 6, 422-428.

Otterbein, L. E., Zuckerbraun, B. S., Haga, M., Liu, F., Song, R., Usheva, A., Stachulak, C., Bodyak, N., Smith, R. N., Csizmadia, E., Tyagi, S., Akamatsu, Y., Flavell, R. J., Billiar, T. R., Tzeng, E., Bach, F. H., Choi, A. M., and Soares, M. P. (2003).
Carbon monoxide suppresses arteriosclerotic lesions associated with chronic graft rejection and with balloon injury. Nat. Med. 9, 183-190.

Pamplona, A., Ferreira, A., Balla, J., Jeney, V., Balla, G., Epiphanio, S., Chora, A., Rodrigues, C. D., Gregoire, I. P., Cunha-Rodrigues, M., Portugal, S., Soares, M. P., and Mota, M. M. (2007). Heme oxygenase-1 and carbon monoxide suppress the pathogenesis of experimental cerebral malaria. Nat. Med. 13, 703-710.

Park, J. G., Yoo, J. Y., Jeong, S. J., Choi, J. H., Lee, M. R., Lee, M. N., Hwa Lee, J., Kim, H. C., Jo, H., Yu, D. Y., Kang, S. W., Rhee, S. G., Lee, M. H., and Oh, G. T. (2011). Peroxiredoxin 2 deficiency exacerbates atherosclerosis in apolipoprotein E-deficient mice. Circ. Res. 109, 739-749.

Phelan, D., Winter, G. M., Rogers, W. J., Lam, J. C., and Denison, M. S. (1998). Activation of the Ah receptor signal transduction pathway by bilirubin and biliverdin. Arch. Biochem. Biophys. 357, 155-163.

Philippidis, P., Mason, J. C., Evans, B. J., Nadra, I., Taylor, K. M., Haskard, D. O., and Landis, R. C. (2004). Hemoglobin scavenger receptor CD163 mediates interleukin-10 release and heme oxygenase-1 synthesis - Antiinflammatory monocytemacrophage responses in vitro, in resolving skin blisters in vivo, and after cardiopulmonary bypass surgery. Circ. Res. 94, 119-126.

Pittock, S. T., Norby, S. M., Grande, J. P., Croatt, A. J., Bren, G. D., Badley, A. D., Caplice, N. M., Griffin, M. D., and Nath, K. A. (2005). MCP-1 is upregulated in unstressed and stressed HO-1 knockout mice: pathophysiologic correlates. Kidney Int. 68, 611-622.

Poss, K. D., and Tonegawa, S. (1997). Heme oxygenase 1 is required for mammalian iron reutilization. Proc. Natl. Acad. Sci. U.S.A. 94, 10919-10924.

Romanoski, C. E., Che, N., Yin, F., Mai, N., Pouldar, D., Civelek, M., Pan, C., Lee, S., Vakili, L., Yang, W. P., Kayne, P., Mungrue, I. N., Araujo, J. A., Berliner, J. A., and Lusis, A. J. (2011). Network for activation of human endothelial cells by oxidized phospholipids. Circ. Res. 109, E27-U52.

Ryter, S. W., and Tyrrell, R. M. (2000). The heme synthesis and degradation pathways: role in oxidant sensitivity. Heme oxygenase has both pro- and antioxidant properties. Free Radic. Biol. Med. 28, 289-309.

Sacerdoti, D., Colombrita, C., Ghattas, M. H., Ismaeil, E. F., Scapagnini, G.,
Bolognesi, M., Volti, G. L., and Abraham, N. G. (2005). Heme oxygenase1 transduction in endothelial cells causes downregulation of monocyte chemoattractant protein-1 and of genes involved in inflammation and growth. Cell. Mol. Biol. 51, 363-370.

Sachais, B. S., Turrentine, T., Mckenna, J. M. D., Rux, A. H., Rader, D., and Kowalska, M. A. (2007). Elimination of platelet factor 4 (PF4) from platelets reduces atherosclerosis in $\mathrm{C} 57 \mathrm{BI} / 6$ and apoE(-/-) mice. Thromb. Haemost. 98, 1108-1113.

Sarady, J. K., Otterbein, S. L., Liu, F., Otterbein, L. E., and Choi, A. M (2002). Carbon monoxide modulates endotoxin-induced production of granulocyte macrophage colonystimulating factor in macrophages. Am. J. Respir. Cell Mol. Biol. 27, 739-745.

Schillinger, M., Exner, M., Mlekusch, W., Domanovits, H., Huber, K., Mannhalter, C., Wagner, O., and Minar, E. (2002). Heme oxygenase1 gene promoter polymorphism is associated with abdominal aortic aneurysm. Thromb. Res. 106, 131-136.

Schwertner, H. A. (1998). Association of smoking and low serum bilirubin antioxidant concentrations. Atherosclerosis 136, 383-387.

Schwertner, H. A., Jackson, W. G., and Tolan, G. (1994). Association of low serum concentration of bilirubin with increased risk of coronary artery disease. Clin. Chem. 40 18-23.

Schwertner, H. A., and Vitek, L. (2008). Gilbert syndrome, UGT1A1 228 allele, and cardiovascular disease risk: possible protective effects and therapeutic applications of bilirubin. Atherosclerosis 198, 1-11.

Sinal, C. J., and Bend, J. R. (1997). Aryl hydrocarbon receptor-dependent induction of cyplal by bilirubin in mouse hepatoma hepa 1clc7 cells. Mol. Pharmacol. 52, 590-599.

Singleton, J. W., and Laster, L. (1965). Biliverdin reductase of guinea pig liver. J. Biol. Chem. 240, 4780-4789.

Siow, R. C., Sato, H., and Mann, G. E. (1999). Heme oxygenase-carbon monoxide signalling pathway in atherosclerosis: anti-atherogenic actions of bilirubin and carbon monoxide? Cardiovasc. Res. 41, 385-394.

Soares, M. P., and Bach, F. H. (2009). Heme oxygenase-1: from biology to therapeutic potential. Trends. Mol. Med. 15, 50-58.

Soares, M. P., Lin, Y., Anrather, J., Csizmadia, E., Takigami, K., Sato, K., Grey, S.T., Colvin, R. B., Choi,
A. M., Poss, K. D., and Bach, F. H. (1998). Expression of heme oxygenase- 1 can determine cardiac xenograft survival. Nat. Med. 4, 1073-1077.

Sriram, V., and Patterson, C. (2001). Cell cycle in vasculoproliferative diseases: potential interventions and routes of delivery. Circulation 103 , 2414-2419.

Stocker, R., and Keaney, J. F. Jr. (2004). Role of oxidative modifications in atherosclerosis. Physiol. Rev. 84, 1381-1478.

Stocker, R., Yamamoto, Y., Mcdonagh, A. F., Glazer, A. N., and Ames, B. N. (1987). Bilirubin is an antioxidant of possible physiological importance. Science 235, 1043-1046.

Sussan, T. E., Jun, J., Thimmulappa, R., Bedja, D., Antero, M., Gabrielson, K. L., Polotsky, V. Y., and Biswal, S. (2008). Disruption of Nrf2, a key inducer of antioxidant defenses, attenuates ApoE-mediated atherosclerosis in mice. PLoS One 3, e3791. doi:10.1371/journal.pone.0003791

Taha, H., Skrzypek, K., Guevara, I., Nigisch, A., Mustafa, S., GrochotPrzeczek, A., Ferdek, P., Was, H., Kotlinowski, J., Kozakowska, M., Balcerczyk, A., Muchova, L., Vitek, L., Weigel, G., Dulak, J., and Jozkowicz, A. (2010). Role of heme oxygenase-1 in human endothelial cells: lesson from the promoter allelic variants. Arterioscler. Thromb. Vasc. Biol. 30, 1634-1641.

Tsuchihashi, S., Livhits, M., Zhai, Y., Busuttil, R. W., Araujo, J. A. and Kupiec-Weglinski, J. W. (2006) Basal rather than induced heme oxygenase-1 levels are crucial in the antioxidant cytoprotection. $J$. Immunol. 177, 4749-4757.

Tulis, D. A., Durante, W., Liu, X., Evans, A. J., Peyton, K. J., and Schafer, A. I. (2001). Adenovirusmediated heme oxygenase-1 gene delivery inhibits injury-induced vascular neointima formation. Circulation 104, 2710-2715.

Wang, L. J., Lee, T. S., Lee, F. Y., Pai, R. C., and Chau, L. Y. (1998). Expression of heme oxygenase- 1 in atherosclerotic lesions. Am. J. Pathol. 152, 711-720.

Wang, X. M., Kim, H. P., Nakahira, K., Ryter, S. W., and Choi, A. M. (2009). The heme oxygenase$1 /$ carbon monoxide pathway suppresses TLR4 signaling by regulating the interaction of TLR4 with caveolin-1. J. Immunol. 182, 3809-3818.

Weis, N., Weigert, A., Von Knethen, A., and Brune, B. (2009). Heme oxygenase-1 contributes to an 
alternative macrophage activation profile induced by apoptotic cell supernatants. Mol. Biol. Cell 20, 1280-1288.

Wilson, H. M. (2010). Macrophages heterogeneity in atherosclerosis - implications for therapy. J. Cell. Mol. Med. 14, 2055-2065.

Wu, D., Nishimura, N., Kuo, V., Fiehn, O., Shahbaz, S., Van Winkle, L., Matsumura, F., and Vogel, C. F. (2011). Activation of aryl hydrocarbon receptor induces vascular inflammation and promotes atherosclerosis in apolipoprotein E-/- mice. Arterioscler. Thromb. Vasc. Biol. 31, 1260-1267.

Wu, T. W., Fung, K. P., Wu, J., Yang, C. C., and Weisel, R. D. (1996). Antioxidation of human low density lipoprotein by unconjugated and conjugated bilirubins. Biochem. Pharmacol. 51, 859-862.

Wuttge, D. M., Eriksson, P., Sirsjö, A., Hansson, G. K., and Stemme, S.
(2001). Expression of interleukin-15 in mouse and human atherosclerotic lesions. Am. J. Pathol. 159, 417.

Yachie, A., Niida, Y., Wada, T., Igarashi, N., Kaneda, H., Toma, T., Ohta, K., Kasahara, Y., and Koizumi, S. (1999). Oxidative stress causes enhanced endothelial cell injury in human heme oxygenase-1 deficiency. J. Clin. Invest. 103, 129-135.

Yamada, N., Yamaya, M., Okinaga, S., Nakayama, K., Sekizawa, K., Shibahara, S., and Sasaki, H. (2000). Microsatellite polymorphism in the heme oxygenase-1 gene promoter is associated with susceptibility to emphysema. Am. J. Hum. Genet. 66, 187-195.

Yamashita, K., Mcdaid, J., Ollinger, R., Tsui, T. Y., Berberat, P. O., Usheva, A., Csizmadia, E., Smith, R. N., Soares, M. P., and Bach, F. H. (2004). Biliverdin, a natural product of heme catabolism, induces tolerance to cardiac allografts. FASEB J. 18, 765-767.
Yan, Z. Q., and Hansson, G. K. (2007). Innate immunity, macrophage activation, and atherosclerosis. Immunol. Rev. 219 187-203.

Yet, S. F., Layne, M. D., Liu, X., Chen, Y. H., Ith, B., Sibinga, N. E., and Perrella, M. A. (2003). Absence of heme oxygenase- 1 exacerbates atherosclerotic lesion formation and vascular remodeling. FASEB J. 17, 1759-1761.

Yilmaz, A., Lochno, M., Traeg, F. Cicha, I., Reiss, C., Stumpf, C., Raaz, D., Anger, T., Amann, K., Probst, T., Ludwig, J., Daniel, W. G., and Garlichs, C. D. (2004). Emergence of dendritic cells in rupture-prone regions of vulnerable carotid plaques. Atherosclerosis 176, 101-110.

Conflict of Interest Statement: The authors declare that the research was conducted in the absence of any commercial or financial relationships that could be construed as a potential conflict of interest.

Received: 13 March 2012; paper pending published: 03 April 2012; accepted: 06 June 2012; published online: 19 July 2012.

Citation: Araujo JA, Zhang $M$ and Yin F (2012) Heme oxygenase-1, oxidation, inflammation, and atherosclerosis. Front. Pharmacol. 3:119. doi: 10.3389/fphar.2012.00119

This article was submitted to Frontiers in Drug Metabolism and Transport, a specialty of Frontiers in Pharmacology. Copyright (c) 2012 Araujo, Zhang and Yin. This is an open-access article distributed under the terms of the Creative Commons Attribution License, which permits use, distribution and reproduction in other forums, provided the original authors and source are credited and subject to any copyright notices concerning any third-party graphics etc. 